Technische

Universität

Berlin

\author{
Felix L. Arens, Alessandro Airo, Jenny Feige, Christof Sager, Uwe \\ Wiechert, Dirk Schulze-Makuch
}

\title{
Geochemical proxies for water-soil interactions in the hyperarid Atacama Desert, Chile
}

Open Access via institutional repository of Technische Universität Berlin

\section{Document type}

Journal article | Accepted version

(i. e. final author-created version that incorporates referee comments and is the version accepted for publication; also known as: Author's Accepted Manuscript (AAM), Final Draft, Postprint)

This version is available at

https://doi.org/10.14279/depositonce-12120

\section{Citation details}

Arens, F. L., Airo, A., Feige, J., Sager, C., Wiechert, U., Schulze-Makuch, D. (2021). Geochemical proxies for water-soil interactions in the hyperarid Atacama Desert, Chile. CATENA, 206, 105531.

https://doi.org/10.1016/j.catena.2021.105531

\section{Terms of use}

()(1) $(9)$ This work is licensed under a Creative Commons Attribution-NonCommercial- NoDerivatives 4.0 International license: https://creativecommons.org/licenses/by-nc-nd/4.0/ 
Accepted manuscript of: F.L. Arens, A. Airo, J. Feige, C. Sager, U. Wiechert, D. Schulze-Makuch, 2021. Geochemical proxies for water-soil interactions in the hyperarid Atacama Desert, Chile. Catena 206, 105531. https://doi.org/10.1016/j.catena.2021.105531

(C) 2021 This manuscript version is made available under the CC-BY-NC-ND 4.0 license https://creativecommons.org/licenses/by-nc-nd/4.0/

\section{Geochemical proxies for water-soil interactions in the hyperarid Atacama Desert, Chile}

(1)

(6)

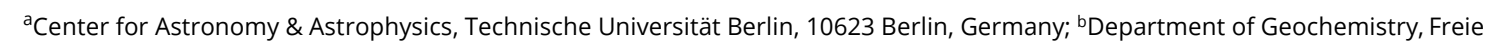
Universität Berlin, 12249 Berlin, Germany; 'German Research Centre for Geosciences (GFZ), Section Geomicrobiology, 14473 Potsdam, Germany; dDepartment of Experimental Limnology, Leibniz-Institute of Freshwater Ecology and Inland Fisheries (IGB), 12587 Stechlin, Germany

*Corresponding author, Hardenbergstraße 36A, 10623 Berlin, Germany, f.arens@tu-berlin.de

(1)

\section{ABSTRACT}

The Atacama Desert is the oldest and driest non-polar desert on Earth. Millions of years of hyperaridity enabled salt accumulations through atmospheric deposition. These salts can serve as proxies to decipher the interaction between water and soil as well as to understand the habitability with changing environmental settings. Therefore, we investigated four soil profiles regarding their mineralogy, salt abundance, and sulfate stable isotopic composition. The profiles were located along an elevation transect in the hyperarid region southeast of Antofagasta, Chile. The two lower sites situated on the distal parts of inactive alluvial fan deposits were subject to occasional fog occurrences. The upper steeper-sloped sites experienced no fog but are subject to minimal erosion. In all soil profiles, sulfates are the dominant salts showing a downward transition from gypsum to anhydrite that is accompanied by an increase of highly soluble salts and a decrease of sulfate $\delta^{34} \mathrm{~S}$ and $\delta^{18} \mathrm{O}$ values. These trends are consistent with downward directed water infiltration during rare rain events causing salt dissolution followed by precipitation within the deeper soil column. This conclusion is also w supported by our Rayleigh fractionation model. We attribute the presence of anhydrite at $>40 \mathrm{~cm}$ depth to the cooccurrence of nitrate and chloride salts, which decreases water activity during sulfate precipitation and therefore drives anhydrite formation. Along the elevation transect, the total salt inventories of each profile show a trend for nitrates and chlorides concentration decreasing with elevation. This observation together with the sulfate stable isotopes indicates a fog-independent source and suggests remobilization of soluble salts through enhanced washout from hillslopes to alluvial fans. These findings are essential for assessing the longterm regional habitability of hyperarid environments and have also relevance for Mars. Keywords: gypsum, anhydrite, stable isotopes, pedogenesis, hyperarid, Atacama Desert 
30 The core of the Atacama Desert (Fig. 1a) is currently hyperarid (mean annual precipitation $<20 \mathrm{~mm} \mathrm{a}^{-1}$ ) and

31 has been a desert for $12 \pm 1$ Ma shifting between arid and hyperarid periods (Jordan et al., 2014). Accordingly,

32 fluvial run-off is minimal and erosion rates are extremely low ranging from 0.2 to $0.4 \mathrm{~m} \mathrm{Ma}^{-1}$

33 (Placzek et al., 2010). Under these circumstances, earthquakes, which are frequent in the region, contribute

34 considerably to down-slope sediment transport through seismic shaking (Quade et al., 2012; May et al., 2019;

35 Sager et al., 2020). Furthermore, the hyperarid conditions prevent the growth of vascular plants and keep the

36 microbial biomass content at extremely low levels of $<10^{-6}$ cells $\mathrm{g}^{-1}$ soil in our study area (Schulze-Makuch et

37 al., 2018), creating a carbon-limited environment (Azua-Bustos et al., 2017). Under these conditions, the soil

$38 \mathrm{CO}_{2}$ concentrations are too low for the formation of significant amounts of carbonates, which are commonly

39 present in arid soils (Ewing et al., 2006). Hence, the Atacama Desert is of interest for studying the dry limits

40 of life and has been used as an analog site for assessing the habitability on Mars (e.g., Warren-Rhodes et al.,

41 2006; Azua-Bustos et al., 2018; Schulze-Makuch et al., 2018; Huang et al., 2020; Shen et al., 2020; Schulze-

42 Makuch et al., 2021).

43 In contrast to arid deserts, precipitation in the hyperarid Atacama Desert is sufficiently low so that even the 44 most soluble salts (e.g., chlorides, nitrates) are not entirely washed out but remain partially in the soil typically 45 at depths of a few meters (Ericksen, 1981). Although many aspects on the origin, formation, and migration of 46 these unique salt accumulations in the Atacama Desert are not fully understood, the following three sources of 47 salts are assumed to dominate: (a) The groundwater in the Atacama Desert is recharged in the Andes mountains, carrying various ions depending on the substrate types (e.g., bedrocks, volcanic deposits, marine sediment) that have been leached during transport (Rech et al., 2003; Pérez-Fodich et al., 2014). The groundwater table is rarely close enough to the surface of the soils to be directly affected by its evaporation.

51 However, at those locations, such as salars, where groundwater-related evaporites are formed they are readily redistributed regionally by aeolian processes (Rech et al., 2003). (b) Stratocumuli clouds developing over the

53 Pacific Ocean carrying dissolved chloride and sulfate ions intercept with the Coastal Range and form advective

54 fog that can migrate several tens of kilometers into the central parts of the hyperarid desert. However, fog

55 migration is limited by the atmospheric inversion layer to altitudes below $1200 \mathrm{~m}$ above sea level (a.s.1.) 
56 (Cereceda et al., 2008; Voigt et al., 2020). (c) Sulfate, nitrate, and perchlorate salts form in the atmosphere by

57 lightning or photochemical reactions and are deposited regionally by dry fall (e.g., Michalski et al., 2004).

The formation conditions of various sulfate minerals found in the Atacama Desert are still under debate (Ewing et al., 2006; Voigt et al., 2020; Ritterbach and Becker, 2020). Laboratory experiments have shown that the temperature and water activity influence the hydration phases of $\mathrm{CaSO}_{4}$, e.g., gypsum $\left(\mathrm{CaSO}_{4} \cdot 2 \mathrm{H}_{2} \mathrm{O}\right)$ and anhydrite $\left(\mathrm{CaSO}_{4}\right)$, the latter mineral being thermodynamically preferred at high temperatures and low water activities (Hardie, 1967). The metastable bassanite $\left(\mathrm{CaSO}_{4} \cdot 0.5 \mathrm{H}_{2} \mathrm{O}\right)$ can be formed by dehydration of gypsum at temperatures above $\sim 80^{\circ} \mathrm{C}$ and low relative humidity (Seufert et al., 2009; Ritterbach and Becker, 2020). The hyperarid condition causes incomplete salt dissolution and limited migration into the soil, which has been shown to result in mass-dependent fractionation of sulfate $\delta^{34} \mathrm{~S}$ and $\delta^{18} \mathrm{O}$ or chloride $\delta^{37} \mathrm{Cl}$ isotopes with depth (Ewing et al., 2008; Amundson et al., 2012). This isotope fractionation depends on the net direction of the water flow and correspondingly, the inverse fractionation patterns were observed in the Atacama Desert at locations where groundwater evaporation dominates, such as salars (Finstad et al., 2016).

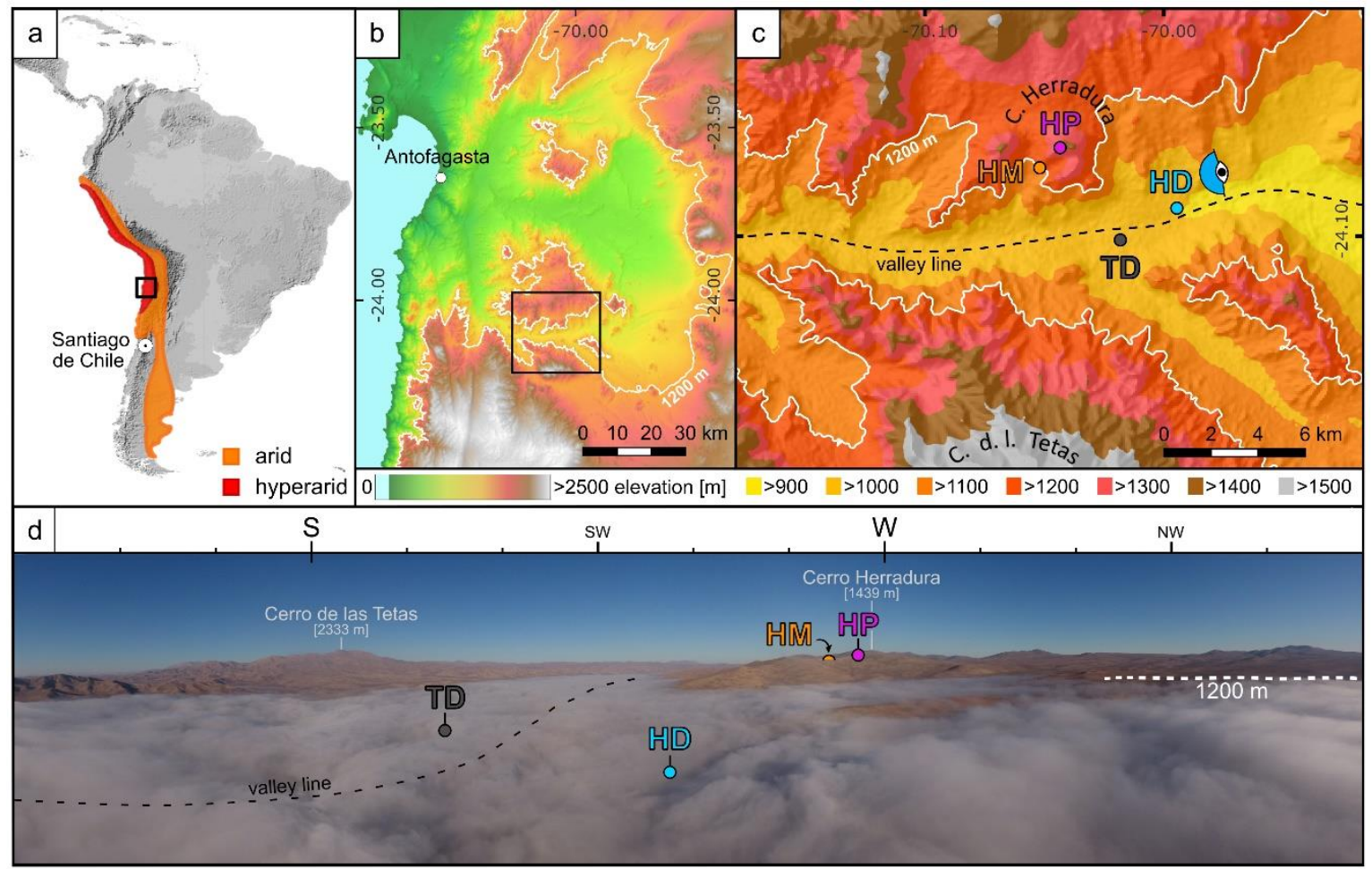

Figure 1 Location of study area. a) overview map shows arid and hyperarid regions in South America (after Houston and Hartley 2003), black rectangle indicates study region; b) topographic map of the study region located southeast of Antofagasta, in the southern part of the hyperarid core of the Atacama Desert (topography based on ASTER DEM(USGS)), 
HD) are located on the southern slopes of the mountain Cerro Herradura and one (TD) on the northern slopes of the mountain Cerro de las Tetas, eye symbol with indicated angle of view marks the position from which the photograph in d) was taken; d) panoramic photograph taken with an unmanned aerial vehicle at $\sim 1400 \mathrm{~m}$ a.s.l. showing the studied valley, covered by fog on 9 August 2019 8:22 AM, reaching the $1200 \mathrm{~m}$ a.s.l. threshold. All elevation values refer to sea level (a.s.l.).

The prevalence of the extremely arid conditions for millions of years in association with an exceptional salt accumulation led to patterned grounds and the unique internal structuring of alluvial soils of the hyperarid Atacama Desert. These soils have been classified into five distinct horizons (Ericksen, 1981) described in the following. The upper $10-30 \mathrm{~cm}$ thick unconsolidated horizon (chusca), often fractured polygonal, consists of a desert pavement sitting on top of a loose, $1-5 \mathrm{~cm}$ thick layer of mainly sand- to clay-sized material that covers a brittle and porous $5-20 \mathrm{~cm}$ thick layer of vesicular texture largely composed of gypsum and anhydrite; referred to as 'vesicular layer' previously described by e.g., Owen et al. (2013). Frequently, on top of the vesicular layer, submerged in the loose material, are hand-palm-sized patty- to bowl-shaped $\sim 5 \mathrm{~cm}$ thick aggregates of almost pure gypsum and anhydrite, called losa. The chusca transitions sharply into a moderately to firmly sulfate-cemented sandy to gravelly lithic sediment (costra). The costra is frequently polygonated by vertical sand wedges that partially extend through the entire horizon of roughly $2 \mathrm{~m}$ in thickness. The horizon below (caliche) is a firmly cemented nitrate-bearing layer of up to $5 \mathrm{~m}$ in thickness, which has been mined in the region for over a century. Further down lies either a salt-cemented regolith (conjelo) or a loose uncemented regolith $(c o b a)$. Due to local variations in morphology and sedimentology the occurrence and development of these horizons can differ substantially. For this study we assumed that all soils are in equilibrium with the hyperarid conditions (i.e., gypsum-anhydrite \& infiltration depth) that prevailed for millions of years. However, in the context of global climate change and the recent increase of precipitation in the region (AzuaBustos et al. 2018), it is to be expected that the here described soil structures are subject to change. The aim of this study is to decipher the pedogenic processes acting under locally different environmental conditions by using the distribution, hydration phases, and isotopic fractionation of salts as geochemical proxies for the longterm interactions of water within the soils. Therefore, we describe and investigated four soil profiles along an elevation transect, which exhibits e.g., different erosion rates and exposure to fog. 


\section{SAMPLING AND METHODS}

102

103

104

105

106

107

108

109

110

111

112

113

114

115

116

117

118

119

120

\subsection{Study site selection and sampling}

All investigated soils are located within a valley $60 \mathrm{~km}$ southeast of Antofagasta, a region commonly known as the 'Yungay area', which we here refer to as 'Yungay valley' (Yungay means "warm valley" in the Quechua language). The Yungay valley crosses the Coastal Cordillera from east to west and is confined by the mountains Cerro Herradura (1439 m a.s.l.) to the North and by the Cerro de las Tetas (2333 m a.s.1.) to the South (Fig. 1). Environmental data, collected over 4 years (1994-1998) in the area, show mean annual precipitation $<2 \mathrm{~mm} \mathrm{a}^{-1}$ and a mean annual temperature of $+16^{\circ} \mathrm{C}$ with a daily temperature range of $\sim 20^{\circ} \mathrm{C}$ in the winter months and $\sim 30^{\circ} \mathrm{C}$ in the summer months (McKay et al., 2003). In our study region rain originates in the southwest over the Pacific Ocean (Houston and Hartley, 2003) and is favored during El Niño years with increased sea surface temperature in the eastern tropical Pacific (Bozkurt et al., 2016). This was the case in the most recent rain event previous to our sampling in March 2015 (Jordan et al., 2015; Bozkurt et al., 2016). Over $30 \mathrm{~mm}$ of total rain caused soil moistening over months, as well as surface overland run-off on hillslopes, subsurface flow, and change in soil mineralogy in our study region (Jordan et al. 2020; Pfeiffer et al., 2021). This rain event was followed by a rain event with a similar magnitude in 2017, which is discussed as a consequence of global climate change (Azua-Bustos et al., 2018). Furthermore, fog is a more frequent water source in the Yungay valley but being limited to $<1200 \mathrm{~m}$ a.s.l., which was also observed by us during the 2018 and 2019 field campaign (Fig. 1d). Groundwater evaporation affecting the soils in the Yungay valley is unlikely because an abandoned mining well nearby was dry down to $40 \mathrm{~m}$ depth, and even the lower elevated Salar Aguas Blancas (961 m a.s.l), $10 \mathrm{~km}$ to the east of the study area, is currently not connected to the groundwater aquifers (Artieda et al., 2015). Our four sampling locations were selected for sampling along an elevation transect ranging from lower fog affected sites to higher non-fog affected terrain. Three study sites are located on the south-facing slope the Cerro Herradura, which are referred to as: Herradura Proximal (HP) (1436 m a.s.l.), located close to the top of the mountain; Herradura Medial (HM) (1217 m a.s.l.) located on the upper mountain slope; and Herradura Distal (HD) (1005 m a.s.l.), located on the lower mountain slope. The fourth site, Tetas Distal (TD) (1021 m a.s.l.), was located on the lower north-facing slope of the Cerro de las Tetas (Fig. 1; Tab. S1). The two lower sites (HD, TD) have been investigated previously and the pits were still accessible (HD: Schulze-Makuch et al., 2018; TD: Ewing et al., 2006, 2008; Sutter et al., 2007; Wilhelm et al., 2017). The HD profile as well as the topmost $140 \mathrm{~cm}$ of the TD profile corresponds to the hyperarid soil 
130 described by Ericksen (1981), while the sediments below have been dated by argon isotope ratio of an ash

131 layer, showing that they are older than 2 Ma and presumably formed under more humid conditions (Ewing et

132 al., 2006). It was also shown that the upper soil layers are volumetric increasing due to atmospheric salt and

133 dust deposition and minimal fluvial erosion (Ewing et al., 2006). Furthermore, a downward decrease of $\delta^{34} S$

134 and $\delta^{18} \mathrm{O}$ was observed, indicating an in-soil fractionation of sulfate $\mathrm{S}$ and $\mathrm{O}$ isotopes due to downward directed

135 meteoric water infiltration (Ewing et al., 2008). These preexisting pits were excavated laterally $>30 \mathrm{~cm}$ to

136 obtain fresh samples, which have been analyzed for this study.

137 The other two pits, selected to be at elevations above (HP) or close to (HM) the upper fog-boundary ( 1200

138 m a.s.1.), were excavated for this study during a field campaign in 2017. Soil samples were collected with a

139 hand shovel and a spatula at increments of $10 \mathrm{~cm}$ down to at least $1 \mathrm{~m}$ depth for each pit. The exact sampling

140 positions were chosen to represent the typical soil at each depth interval, especially avoiding the sampling of

141 the sand wedges.

142 2.2. X-ray diffraction (XRD)

143 Pristine soil samples were homogenized and ground manually to powder for analyzing the bulk salt

144 mineralogy. XRD analysis of crushed soil samples was performed by using a powder diffractometer Empyrean

145 (Malvern Panalytical, Netherlands), at the Laboratory of Mineralogy at the Freie Universität Berlin,

146 performing step scanning with a strip detector measuring 255 steps simultaneously. The X-ray source is a $\mathrm{Cu}$

$147 \mathrm{~K} \alpha$ radiation $(\mathrm{K}$-alpha1 $=1.540598 \AA$ A, K-alpha2=1.54439 $\AA$ ) with a performance of $40 \mathrm{kV}$ and $40 \mathrm{~mA}$. A step

148 interval of $0.013^{\circ} 2 \Theta$ with a step-counting time of $20 \mathrm{~s}$ was used in a scanning range from $10^{\circ}$ to $90^{\circ} 2 \Theta$.

149 Finally, a semi-quantitative evaluation of all the results was conducted with the software High Score (Malvern

150 Panalytical, Netherlands) and the PDF-2 (International Center for Diffraction Data, USA) database.

\section{2.3. Soluble weight loss}

15250 to $150 \mathrm{~g}$ of pristine soil, depending on maximum grain size and cementation, was leached in two steps to

153 determine the weight percent (wt\%) of soluble salts in each sample. In the first step, one-liter deionized water

154 was used to leach the highly soluble salts and in the second leaching procedure with multiple sequential

155 leaching steps, 0.2 molar hydrochloric acid $(\mathrm{HCl})$ was added in amounts sufficient for a complete dissolution

156 of all salts including sulfates. To ensure this, $2 \mathrm{ml}$ leachate of each step was evaporated and checked for visible

157 precipitants. Afterwards the samples were dried and weighed again for determining the weight loss related to

158 the soluble fraction. Repeated measurements gave a reproductivity of $<5 \%(\mathrm{n}=3)$ variation. 


\subsection{Ion chromatography}

The leachates of the above-described method for soluble weight loss were used to determine the concentration of sulfate $\left(\mathrm{SO}_{4}^{-2}\right)$, chloride $\left(\mathrm{Cl}^{-}\right)$and nitrate $\left(\mathrm{NO}_{3}{ }^{-}\right) . \mathrm{Cl}^{-}$and $\mathrm{NO}_{3}{ }^{-}$concentrations were solely determined on the water leachate. $\mathrm{SO}_{4}{ }^{-2}$ was determined on water leachate and the pooled $\mathrm{HCl}$ leachate, measured separately, and corrected for the leachate solution quantity. The analysis was conducted by using capillary electrophoresis (CE) chromatography 3D CE G1600A (Hewlett-Packard, USA) at the Department of Soil Science of the Technische Universität Berlin. Carbonate ions are lost due to $\mathrm{CO}_{2}$-degassing and therefore carbonates cannot be measured with this method. Performing the procedure several times on the same sample yields a variation in reproducibility of $<10 \%(\mathrm{n}=3)$.

\subsection{Stable isotope analysis}

Isotope ratios measurements of sulfur and oxygen were performed on sulfates. The isotope-ratio of ${ }^{34} \mathrm{~S}$ and ${ }^{32} \mathrm{~S}$ $\left(\delta^{34} \mathrm{~S}\right)$ are related to Vienna Canyon Diablo Troilite $(\mathrm{VCDT})$ and ${ }^{18} \mathrm{O}$ and ${ }^{16} \mathrm{O}\left(\delta^{18} \mathrm{O}\right)$ are related to Vienna Standard Mean Ocean Water (VSMOW). Therefore, the water- and HCl-leachates of each sample were pooled under consideration of the leached volume. Barium chloride was added to precipitate barium sulfate $\left(\mathrm{BaSO}_{4}\right)$. The precipitate was filtered, rinsed with Millipore water and dried at $70^{\circ} \mathrm{C}$ for 3 days. Samples duplicates were weighed into tin capsules and vanadium pentoxide $\left(\mathrm{V}_{2} \mathrm{O}_{5}\right)$ was added as a catalyst for $\delta^{34} \mathrm{~S}$ analysis. These capsules were combusted in a furnace operating at $1000^{\circ} \mathrm{C}$ with $\mathrm{O}_{2}$ using a gas chromatograph, which separates $\mathrm{SO}_{2}$ from other combustion products. The pure $\mathrm{SO}_{2}$ was then measured for the $\delta^{34} \mathrm{~S}$ values. For $\delta^{18} \mathrm{O}$ analysis, solely $\mathrm{BaSO}_{4}$ precipitate of taken samples was weighed within silver capsules. Sulfate oxygen was converted to CO by pyrolysis at $1400{ }^{\circ} \mathrm{C}$. The $\delta^{34} \mathrm{~S}$ and $\delta^{18} \mathrm{O}$ measurements were performed with a mass spectrometer MAT-253 (Thermo Fisher Scientific, USA) combined with a Eurovector elemental analyzer (HEKAtech, Germany) at the Institute of Geological Sciences, Freie Universität Berlin. The measured isotope values $\delta^{34} \mathrm{~S}$ and $\delta^{18} \mathrm{O}$ were corrected and standardized based on in-house sulfate $\left(\mathrm{K}_{2} \mathrm{SO}_{4}\right)$ standard and international sulfate $\left(\mathrm{BaSO}_{4}\right)$ standards NBS-127, IAEA-SO5 and -SO6 and sulfide ( $\left.\mathrm{Ag}_{2} \mathrm{~S}\right)$ IAEA-S-1 and -2. Reproducibility of the analyses is $\pm 0.3 \%$ ( $2 \mathrm{SD}$ ) for $\delta^{34} \mathrm{~S}$ and $\pm 0.6 \%$ (2SD) for $\delta^{18} \mathrm{O}$.

\subsection{Rayleigh fractionation model}

We applied the Rayleigh fractionation model, as described by Criss (1999), to derive the fractionation effects for the case of downward migration of sulfate solutions. The model describes the water transport and precipitation of sulfate in each layer, which increases $\delta^{34} \mathrm{~S}$ and $\delta^{18} \mathrm{O}$ in the solid fraction compared to the 
remaining dissolved fraction. Hence, for $\delta^{34} \mathrm{~S}$ (and similarly for $\delta^{18} \mathrm{O}$ ) in the dissolved (d) and the cumulative solid (s) fractions at depth $\mathrm{z}$ the Rayleigh model in $\delta$ notation states that

$$
\delta_{d}{ }^{34} S(z)=\left(\delta_{d, 0}{ }^{34} S(z)+1000\right) f^{\alpha-1}-1000[\%],
$$

Equation (2) was derived from the mass balance equation

$$
\left(f_{s}(z)+f_{d}(z)\right) \delta_{d, 0}{ }^{34} S(z)=f_{d}(z) \delta_{d}{ }^{34} S(z)+f_{s}(z) \delta_{s}{ }^{34} S(z),
$$

by inserting $\delta_{\mathrm{d}}(\mathrm{z})$ from equation (1) into equation (3) and rearranging results. The dimensionless isotopic fractionation factor $\alpha$ is defined as the ratio of the isotope ratios in the heavy (solid) to the light (dissolved) fraction, i.e. $\alpha>1$, and which is related to the isotope enrichment factor $\varepsilon$ (in \%o) by

$$
\alpha=\frac{\epsilon}{1000}+1
$$

The process variable $\mathrm{f}$ in layer $\mathrm{z}$ is defined as the ratio of the dissolved fraction $\mathrm{f}_{\mathrm{d}}$ remaining after precipitation to its total inventory,

$$
f(z)=\frac{f_{d}(z)}{f_{d}(z)+f_{s}(z)},
$$

where $\mathrm{f}_{\mathrm{s}}(\mathrm{z})$ is the layer-thickness (d)-weighted and normalized solid fraction measured in layer $\mathrm{z}$,

$$
f_{s}(z)=\frac{d(z) S O_{4}^{2-}(z)}{\sum_{z} d(z) S O_{4}^{2-}(z)}
$$

with $\mathrm{SO}_{4}{ }^{2-}$ being the sulfate concentrations in $\mathrm{mg} \mathrm{g}^{-1}$, and

$$
f_{d}(z)=f_{d}(z-1)-f_{s}(z)
$$


205 We used isotope enrichment factors $\varepsilon_{s}=2.0 \%$ for sulfur and $\varepsilon_{0}=3.3 \%$ for oxygen (Van Driessche et al., 206 2016). We assumed that at the beginning of the Rayleigh process the entire reservoir was present in dissolved 207 form, hence $\mathrm{f}=\mathrm{f}_{\mathrm{d}}=1$. In order to derive the initial values for $\delta_{\mathrm{d}, 0}{ }^{34} \mathrm{~S}$ (and similarly for $\delta_{\mathrm{d}, 0}{ }^{18} \mathrm{O}$ ) in the topmost 208 layer, we calculate the layer-thickness- and concentration-averaged mean value from all layers, with

$$
\delta_{d, 0}{ }^{34} \quad S=\frac{\sum_{z} d(z) \times S O_{4}(z) \times \delta_{\text {sample }}{ }^{34} S}{\sum_{z} d(z) \times S O_{4}(z)}[\% 0],
$$

210 where $\delta_{\text {sample }}^{34} \mathrm{~S}$ are the measured values, and $\mathrm{SO}_{4}{ }^{2-}(\mathrm{z})$ the measured concentrations. The corresponding $\delta$ 211 values for layers $\mathrm{z}$ below the topmost layer were calculated with equation (1) and further used as input for $\mathrm{z}+1$, e.g. $\delta_{\mathrm{d}}{ }^{34} \mathrm{~S}(\mathrm{z})=\delta_{\mathrm{d}, 0}{ }^{34} \mathrm{~S}(\mathrm{z}+1)$

\section{3. RESULTS}

214 The investigated soils lie on slopes between 1005 and $1436 \mathrm{~m}$ a.s.l., increasing in steepness from distal (HD,

215 TD) to proximal (HP) in relation to the sediment source (Fig. 2a; Table S1). Weighted average stable isotope 216 values for each soil profile were calculated considering the sampling-interval and the sulfate content (Fig. 2b).

217 It shows that the highest elevated soil (HP) compared to the lowest (HD) contain sulfates with $2.3 \%$ higher $218 \delta^{34} \mathrm{~S}$ values and $2.6 \%$ lower $\delta^{18} \mathrm{O}$ values. Comparing the soils within a similar elevation on the Cerro de las 219 Tetas slope (TD) with the Cerro Herradura slope (HD) indicates variability in $\delta^{34} \mathrm{~S}$ values of $1.5 \%$ and $\delta^{18} \mathrm{O}$ 220 values of $2 \%$, respectively. These relations of the average isotope values are consistent, independent of the considered soil depth (Fig. S2). Figure 2c presents the total anion inventory for each soil profile, calculated for a soil column with a surface area of $1 \mathrm{~m}^{2}$ and an estimated bulk soil density of $1000 \mathrm{~kg} \mathrm{~m}^{-3}$. All soils accumulated high amounts of sulfates $\left(>200 \mathrm{~kg} \mathrm{~m}^{-2}\right)$, showing signs of salt-heave and -shattering, resulting in siliciclastic clasts embedded within a sulfate-dominated matrix (e.g., Fig. S3b). Figure 3a shows the schematic build-up of all four soil profiles. The two soils at highest elevation (HP, HM) shift at around $1 \mathrm{~m}$ depth into either unweathered shattered bedrock fragments of a few $\mathrm{mm}$ in diameter (HP) (Fig. S2), or into large unweathered and angular intrusive rock-fragments (HM) (Fig. S3). Fluvial run-off occurs predominantly on steep hillslopes, which recently has been recorded during heavy rain events in 2015 and 2017. During these events, new run-off incisions and small debris flows on the slopes of Cerro Herradura formed (Fig. S4). The other two soils residing on top of inactive alluvial fans do not show sedimentary indications of fluvial transport.

231 However, they contain mostly well-rounded partially chemically weathered clasts deriving from the alluvial 
232 deposits and partially embedded within a sulfate cemented matrix (Fig. S5). At the TD site, the sediments

233 below $1.4 \mathrm{~m}$ depth graduate into fine-grained calcite-cemented paleosol containing plant remains (Fig. S6).

234 A commonality to all soil surfaces is the $10-30 \mathrm{~cm}$ thick chusca horizon (Fig. 3c; Fig. S3c). Losas are embedded within the chusca (Fig. S7), can contain small amounts of anhydrite (Fig. 3). They are absent at HP and only moderately developed at HM, but are ubiquitous and largest in size at the two lower sites (HD, TD). The same trend applies to the degree of ground patterning, which is characterized by soil segmentation into sulfate-cemented polygons of a few meters in diameter. These polygons are separated by downward-narrowing wedges of poorly cemented and vertically layered sediments (Fig. 3; Fig. S5, S6). While polygonation is absent at HP, these wedges become wider and deeper with decreasing site-elevation and reach down to the costra or caliche horizons at HD and TD, respectively.

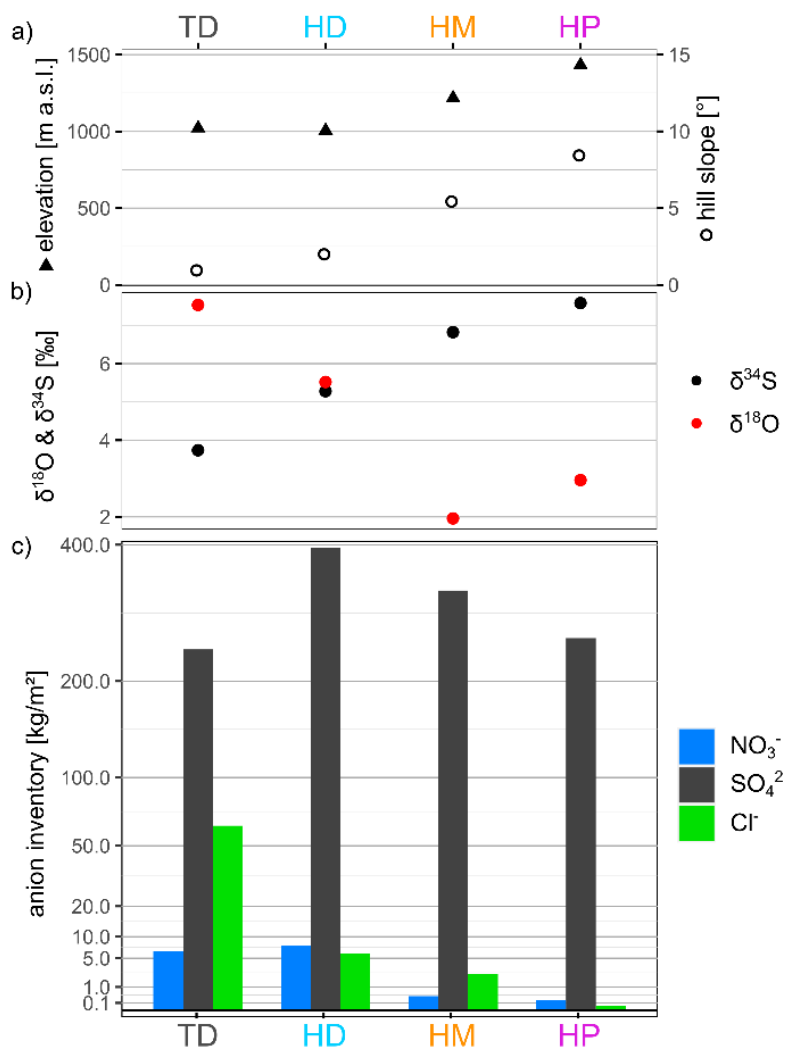

Figure 2 Bulk comparison for each soil profile (Tab. S1). a) elevation and hill slope; b) total weighted average sulfate $\delta^{34}$ S and $\delta^{18} \mathrm{O}$ (For TD only values down to $112 \mathrm{~cm}$ depth from Ewing et al. (2008) are considered, as values below are inconsistent). These trends with soils depth are corroborated in the supplement (Fig. S1); c) total nitrate, sulfate, and 
a) soil profile
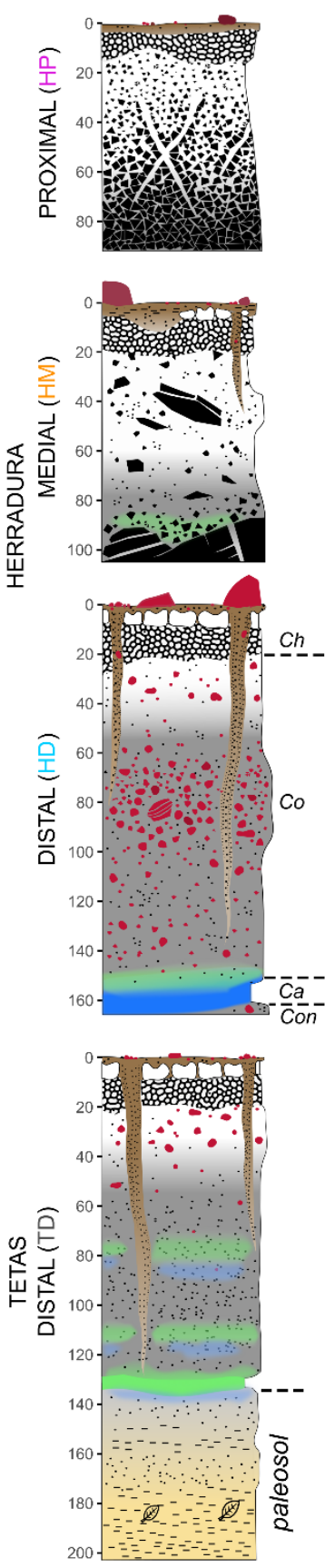

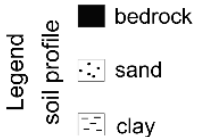

b)

anion concentration $[\mathrm{mg} / \mathrm{g}]$
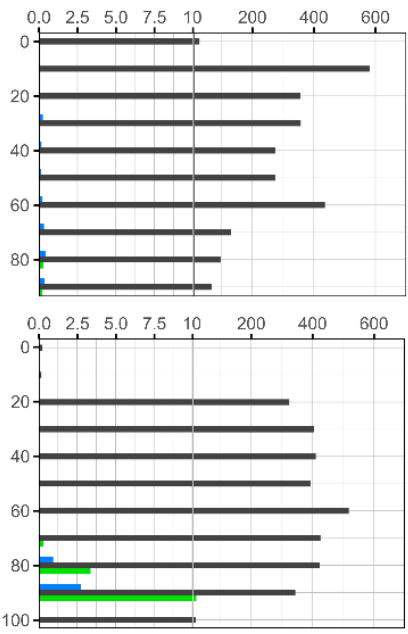

100
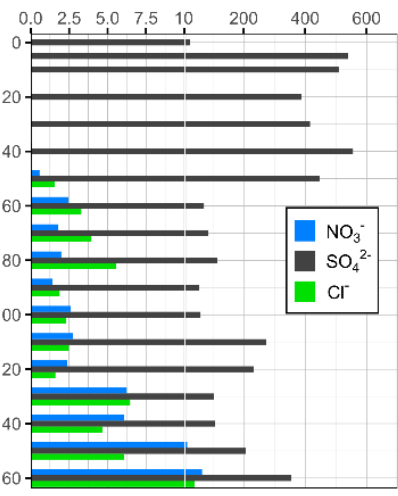

\begin{tabular}{llllllll}
0.0 & 2.5 & 5.0 & 7.5 & 10 & 200 & 400 & 600 \\
\hline
\end{tabular}

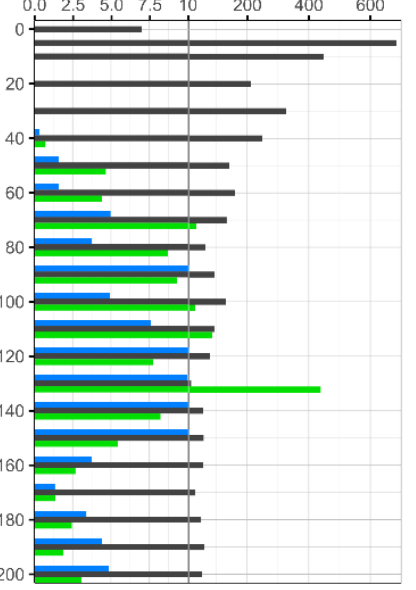

d) sulfate $\delta^{34} \mathrm{~S} \& \delta^{18} \mathrm{O}$

salt mineralogy
(semi.quant.)
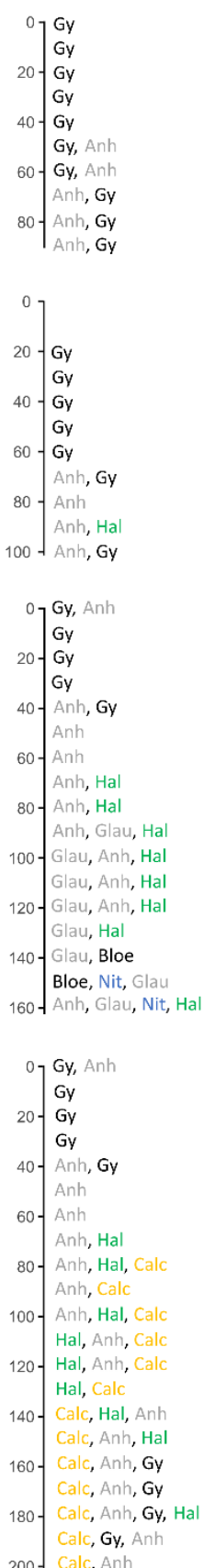

200 Calc, Anh
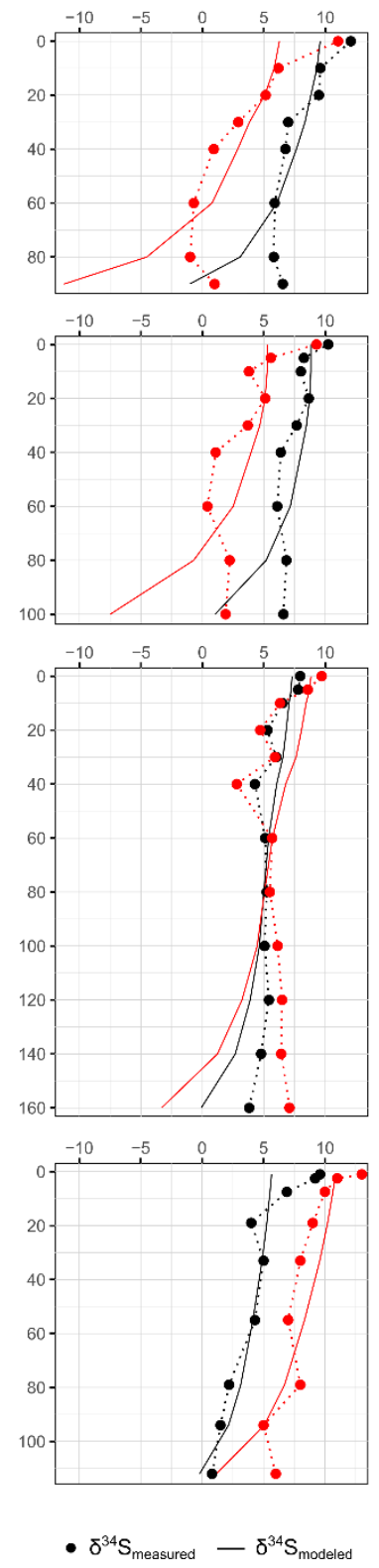

- $\delta^{18} \mathrm{O}_{\text {measured }}-\delta^{18} \mathrm{O}_{\text {modeled }}$

\section{gypsum dominated

Figure 3 Geochemical results for each soil profile, depth in $\mathrm{cm}$ (Tab. S2). a) profile sketch (Ch = chusca, Co=costra,

$249 \mathrm{Ca}=$ caliche, Con=conjelo); b) anion concentration of $\mathrm{SO}_{4}^{2-}, \mathrm{Cl}^{-}, \mathrm{NO}_{3}^{-}$vertical axis scale changes at $20 \mathrm{mg} \mathrm{g}^{-1}$ to visualize

low and high concentrations; c) salt mineralogy by XRD, starting from the most abundant to minor fraction Gy = gypsum; 
254 The concentrations of chlorides and nitrates along the investigated transect generally decrease from low to 255 high elevations (Fig. 2c, Tab. S1). Within each soil profile, the chlorides and nitrates are concentrated at depth below $40-60 \mathrm{~cm}$. However, we do not observe a significant correlation between total soil sulfate concentration and site elevation (Fig. 2c). Sulfates are the most abundant salt in all soils but show an overall downward decrease in amount. Within each soil profile, sulfate concentrations are the highest in the chusca horizon occurring in the form of the vesicular layer (gypsum) and if present also as losas (gypsum and minor anhydrite) (Fig. 3b, c). In the lower part of the HD profile, highly soluble sulfates (glauberite and bloedite) accumulate, following the trend of a downward increase in concentrations of the more soluble salts (Fig. 3c). Within the costra horizon, gypsum transitions consistently into anhydrite below half a meter depth. The anhydrite detected by XRD was exclusively anhydrite-II (if not mentioned otherwise, we use the term 'anhydrite' synonymously for 'anhydrite-II').

Our stable isotope data for the profiles HP, HM, and HD shows an overall decrease in $\delta^{34} \mathrm{~S}$ and $\delta^{18} \mathrm{O}$ values with depth, being most prominent within the first half meter; an observation made previously by Ewing et al. (2008) for the TD profile (Fig. 3d). Applying our Rayleigh model with a downward water flow results in a similar trend as the measured values (Tab. S2), while modeling the inverse water flow results in an anticorrelation in comparison with the measured values (Fig. S8).

\section{DISCUSSION}

\subsection{Elevation-related soil attributes}

272 The HD and TD soil profiles located on inactive alluvial fan deposits correspond well to the hyperarid soil

273 type described by Ericksen (1981). Due to the gentle slope and porous chusca horizon surface, rainwater usually infiltrates entirely into the subsurface (Pfeiffer et al., 2021; Sager et al., 2021). As a result of minimal erosion, the accumulation of salts results in a net deposition (Ewing et al., 2006). The two upper soils (HP, HM) are less mature, exhibiting only little developed polygons and little to no losas. Furthermore, the rapid transition into poorly weathered bedrock and the occasional fluvial run-off on higher elevated steeper sloped surfaces is consistent with these sites being subject to net erosion as proposed previously (Placzek et al., 2010). However, the erosional rates are sufficiently low for allowing the accumulation of substantial amounts of salts through atmospheric deposition, mainly sulfates. Although the absence of the surface-near losas at the HP site 
might reflect an elevated erosion rate, we cannot exclude that their formation required frequent moisturization by fog, which does not reach the upper sites. The sulfate-rich vesicular layer is ubiquitous in the study area and of a similar extent at all sites (Fig. 3a), indicating a relatively rapid formation independent of elevation and sedimentary setting. These observations are consistent with a formation mechanism of the vesicular layer mediated through repetitive eolian input of clays and salts as well as little rainwater infiltration and evaporation; a formation process also proposed for the analogous carbonate-rich vesicular layer found in the arid soils of the Mojave Desert, North America (McFadden et al., 1998; Anderson et al., 2002). In the case of the hyperarid Atacama Desert the cooccurring salt dissolution and reprecipitation, as well as hydration and dehydration of sulfates can play an important role in the formation of vesicular structure (Pfeiffer et al., 2021).

Furthermore, both upper profiles (HP, HM) contain fewer amounts of the highly soluble nitrates and chlorides (Fig. 2c), even though we cannot preclude a higher abundance of nitrates and chlorides at greater depth. However, we assume this not to be the case because of the rapidly decreasing total salt content and pore space at both sites. Consequently, the lower amounts of these salts can be either due to lower input or higher output rates. Nitrates, which are formed in the atmosphere (Michalski et al., 2004; Ewing et al., 2007) and assumed to be initially deposited homogeneously without significant elevation-dependent input rate variations, would therefore need to be subject to higher output rates at the upper sites. In contrast, the major sources of chlorides in the region are basin-associated salars connected to the groundwater (Pérez-Fodich et al., 2014) and oceanderived fog (Voigt et al., 2020). Thus, we cannot exclude that the decrease in chlorides with increasing elevation is related to lower input rates. We conclude that downslope aqueous wash-out and a subsurface migration are responsible for the lower concentrations of nitrates and perhaps also chlorides in the upper soils (HP, HM) in comparison to the lower soils (HD, TD) (Fig. 4). Over time, the highly soluble salts accumulate within the flat alluvial fans, which, under more humid climate conditions, would be washed out or in the case of nitrates could be metabolized by microorganisms. The less soluble sulfates are similarly abundant in all four soils indicating that the little precipitation is only able to wash-out and transport downhill the most soluble salts.

306 The weighted average $\delta^{34} \mathrm{~S}$ values of all the sulfates present within each of the four soil profiles range from 3073.7 to $7.6 \%$ (Fig. 2 b), indicate a dominantly volcanic sulfur source $(0-5 \%$ ) (Rech et al., 2003). The values from the higher elevated sites (HP, HM) being slightly above the volcanic isotope values points to an additional source of heavier sulfur. Although marine-derived fog contains heavy sulfates $\left(\delta^{34} \mathrm{~S} \sim 21 \%\right.$ ), we consider this 
311 the pattern of fog migration has changed through time. Alternatively, it is conceivable that beyond the in-soil

312 vertical isotopic fractionation a long-distance downslope isotopic fractionation occurred over geological 313 timescales. Contrary to the $\delta^{34} \mathrm{~S}$ values, the weighted average $\delta^{18} \mathrm{O}$ values, ranging from 2.0 to $7.5 \%$, are lower 314 at the higher elevated sites (HP, HM). The higher $\delta^{18} \mathrm{O}$ values at the lower sites (HD, TD) could indicate an exchange of oxygen between sulfate and water, a process that causes strong isotopic fractionation of up to $31 \%$ but occurs at a slow rate of $10^{5}$ years at $25^{\circ} \mathrm{C}$ (Lloyd, 1968; Zeebe, 2010). We assume that the lower sites

317 (HD, TD) are subject to longer wetting periods, because of their larger catchment area and enhanced infiltration capacity. This would explain why they exhibit higher $\delta^{18} \mathrm{O}$ values compared to the upper sites (HP, HM).

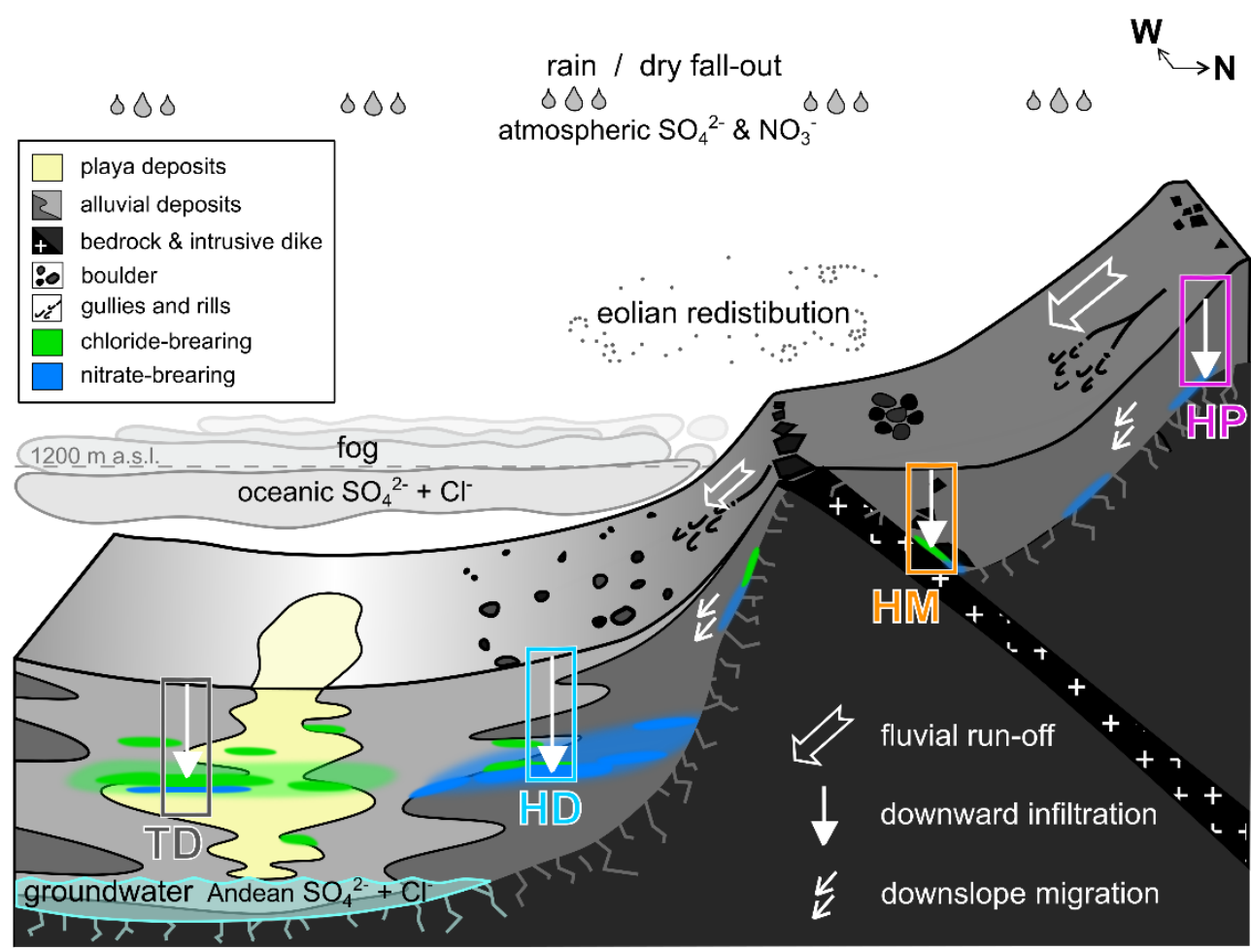

Figure 4 Sketch of salt input and distribution within the Yungay Valley. $\mathrm{SO}_{4}^{2-}$ and $\mathrm{NO}_{3}^{-}$are brought into the system

homogeneous by dry fall-out, eolian dust, or rain. Cl' is more limited to lower elevation as the source is mainly the ocean, distributed by fog and eolian dust or saline groundwater, also redistributed by eolian dust. Once in the soil, salts can be redistributed again. Rare rain events lead to downward in-soil salt transport. However, there are indications on rare 
329 Our individual soil profile data indicates that water-soil interactions in our study area are dominated by short330 distance downward rainwater infiltration, independent of elevation and sedimentological setting. The 331 downward increase of the salt solubility reflects the dominant direction and reach of water flow since the 332 Pleistocene (Ewing et al., 2006). Furthermore, all profiles show a systematic decrease of $\delta^{34} \mathrm{~S}$ and $\delta^{18} \mathrm{O}$ sulfate 333 values to at least a depth of $40 \mathrm{~cm}$, as was observed by Ewing et al. (2008) for the TD profile, which is 334 consistent with a Rayleigh fractionation resulting from sulfate precipitating out of downward migrating water.

335 Although, the modeled and measured $\delta^{34} \mathrm{~S}$ and $\delta^{18} \mathrm{O}$ data show a similar downward trend of decreasing values, 336 we find the following two main deviations: (1) Within the upper half meter the measured values decrease more rapidly than the modeled data. (2) Below half a meter the measured values decrease only a little or even

338 increase with depth. These discrepancies indicate that the here used simple Rayleigh model can only replicate the general trend of isotopic distribution within the soils. Hence, the processes controlling isotope fractionation in the natural environment are more complex and could include the following aspects: the presence of soluble salts in the lower soil layers elevates the salinity during $\mathrm{CaSO}_{4}$ precipitation, which is known to influence isotope fractionation (Van Driessche et al., 2016). The porous and permeable chusca horizon is most frequently exposed to meteoric water and therefore is the most dynamic horizon, which could explain why measured isotopic fractionation is stronger than seen in the modeled data. This upper soil horizon is also affected by salt efflorescence after rain events and through artificial rain experiments (Sager et al., 2021, Pfeiffer et al., 2021), which indicates more complex water pathways at the surface than dominant downward migration, influencing potentially also the isotopic fractionation. Furthermore, rainwater infiltration is not homogeneous and is most intense along the sand wedges (Owen et al., 2013), presumably affecting the lateral isotope pattern. The deviation of the modeled versus measured data in the lower soil layers, especially the bottom value, likely relates to sulfate migration not terminating at the bottom of the considered depth as assumed in our model.

Under ideal conditions isotope fractionation of a single sulfate source should result in a systematic correlation of the $\delta^{34} \mathrm{~S}$ and $\delta^{18} \mathrm{O}$ values that reflect the ratio of the enrichment factors $\left(\varepsilon_{0} / \varepsilon_{S}=1.7 \pm 0.3 \%\right.$ ) (Van Driessche et al., 2016). Fig. 5 shows the correlation between $\delta^{34} \mathrm{~S}$ and $\delta^{18} \mathrm{O}$ values and their coefficient of determination $\left(\mathrm{R}^{2}\right)$ for each soil profile. Additionally, this data was divided into the upper $50 \mathrm{~cm}$, which is dominated by gypsum and the lower section, which is dominated by anhydrite and the occurrence of more soluble salts. This correlation is highly significant for the upper profiles HP and HM with $\mathrm{R}^{2}$ values $>0.9$ independent of the considered soil depth. Equally significant is the correlation for the upper $50 \mathrm{~cm}$ of the HD profile, while the 

the correlation is moderately independent of the considered soil depth.

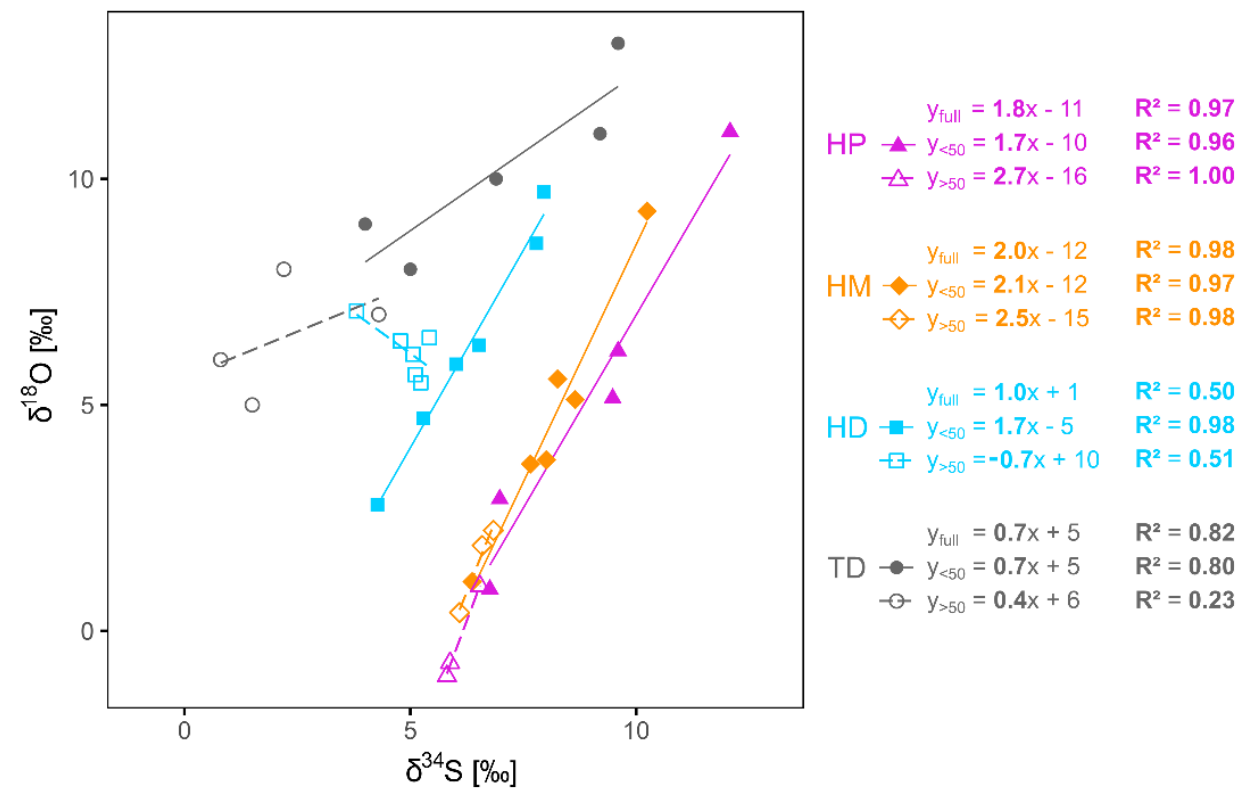

Figure 5 Correlation between $\delta^{34} S$ and $\delta^{18} O$ for each soil profile. Values for TD site from Ewing et al. (2008). The linear regressions are plotted for the values above (solid/filled) and below (dashed/void) $50 \mathrm{~cm}$ depth. The equations for the linear regressions as well as the corresponding coefficient of determination $R^{2}$ are given for each profile: entire profile (yfull), values above $50 \mathrm{~cm}$ depth $(y<50)$, and values below $50 \mathrm{~cm}$ depth $(y>50)$.

The values of the two upper soil profiles (HP, HM) follow this trend (i.e., the slope) with high significance independently of the considered soil depth (Fig. 5). This supports the assumption that these soils have only a single sulfate source entering from the top, which is consistent with an erosive soil.

Although we find the same systematic correlations of the $\delta^{34} \mathrm{~S}$ and $\delta^{18} \mathrm{O}$ values at the HD site in the upper half meter, below we observe an anticorrelation between the $\delta^{34} \mathrm{~S}$ and $\delta^{18} \mathrm{O}$ values. This change in isotope pattern might result from a change in fractionation due to the presence of highly soluble sulfates (in the case of HD glauberite and bloedite), which presumably have a different fractionation factor (Seal et al., 2000) or it could be due to long-term oxygen exchange with water causing an isotopic fractionation as described in section 4.1.

373 At the TD site the correlations of the $\delta^{34} \mathrm{~S}$ and $\delta^{18} \mathrm{O}$ values are slightly lower $\left(\mathrm{R}^{2} \sim 0.8\right)$ and have a different $\varepsilon_{\mathrm{O}} / \varepsilon_{\mathrm{S}}$ value of 0.7 (Fig. 5). This difference might be due to the varying sediment source (Cerro de las Tetas) and/or resulted from the interaction with ground water in the past (>2 Ma) during arid conditions. 
377 The occurrence of anhydrite in the region has been interpreted as an indicator for long-term hyperaridity

378 (Ewing et al., 2006; Voigt et al., 2020). Ewing et al. (2006) have interpreted that the lower anhydrite-dominated

379 soil at the TD site is caused by the low mean soil relative humidity, reported to be only $20 \%$ (Warren-Rhodes

380 et al., 2006), while the upper gypsum-dominated soil is subject to enhanced and more frequent wetting and

381 hydration. More recently, Voigt et al. (2020) have shown in the Atacama Desert a correlation between the 382 regional aridity and the occurrences of anhydrite and gypsum within surface-near soils $(<40 \mathrm{~cm}$ depth) located 383 between $25^{\circ} \mathrm{S}$ and $19^{\circ} \mathrm{S}$ latitudes, where anhydrite dominated in the northern, most arid regions. Other studies 384 have found a shift of hydration phases of near-surface calcium sulfates after the extreme rain event in 2015 385 (e.g., Schulze-Makuch et al., 2018; Pfeiffer et al., 2021). Considering the proposed dehydration of gypsum 386 after a rain event by high surface temperatures reaching $60^{\circ} \mathrm{C}$, Pfeiffer et al. (2021) concluded that the 387 uppermost chusca horizon is subject to rapid dehydration-hydration cycles. In the context of our findings, we 388 propose that the formation of anhydrite within the shallow chusca horizon relies on high temperatures, while 389 the systematic transition from gypsum to anhydrite within the costra horizon at $\sim 50 \mathrm{~cm}$ depth (Fig. $3 \mathrm{c}$ ) is 390 related to the presence of nitrates and/or chlorides and only indirectly linked to aridity. The interrelation is based on the following reasons:

392 Initial atmospheric sulfate deposition is dominated by gypsum because anhydrite formation is kinetically hindered under conditions of rapid rainwater evaporation (Freyer and Voigt, 2003). Thus, the gypsumanhydrite transformation must occur post-depositional through either dry dehydration or gypsum-dissolution followed by slow anhydrite-crystallization. Laboratory experiments, performed over several months, could only show dry dehydration of gypsum to occur above $85^{\circ} \mathrm{C}$ forming bassanite $\left(\mathrm{CaSO}_{4} \cdot 0.5 \mathrm{H}_{2} \mathrm{O}\right)$ and anhydriteIII $\left(\mathrm{CaSO}_{4}\right)$ (Seufert et al., 2009). A more recent study from Ritterbach and Becker (2020) could demonstrate that the dehydration of gypsum to bassanite can occur already at $76^{\circ} \mathrm{C}$ for an experiment duration of $60 \mathrm{~h}$. However, such high temperatures do not typically occur in our study region (McKay et al., 2003) and we did not detect any bassanite or anhydrite-III within the chusca, which lets us conclude that dry dehydration does not play a significant role in the formation of anhydrite. However, the formation of anhydrite from a saturated

$402 \mathrm{CaSO}_{4}$ solution through slow precipitation can occur already at temperatures above $42 \pm 2^{\circ} \mathrm{C}$ (Charola et al., 403 2007). Temperatures as high as that have been recorded in $10 \mathrm{~cm}$ depth close to our study site, after a rain 404 experiment when the soil moisture still reached $100 \%$, indicating the presence of liquid water (Sager et al., 405 2021). Considering that these temperatures can be reached at shallow depth and that rainwater can dampen the 
soil at 10-30 cm depth for months (Schulze-Makuch et al., 2018; Sager et al., 2021; Jordan et al., 2020), we assume that the formation of anhydrite in the chusca horizon can occur through precipitation out of solarheated water after a rain event with retention time of several months. At depths below $50 \mathrm{~cm}$ the temperatures remain too low for this process to occur. However, if highly soluble salts are additionally present that reduce the water activity of the solution, the formation of anhydrite can occur at lower temperatures, e.g., at $22^{\circ} \mathrm{C}$ in saturated sodium chloride solution based on thermodynamic calculations and laboratory experiments (Hardie, 1967; Freyer and Voigt, 2003). This causal connection between electrolyte-presence and anhydrite formation is supported by the occurrence of anhydrite in saline environments such as supratidal salt flats (sabkhas) (Wilson et al., 2013); environments that are not hyperarid but rather hot and more humid. The electrolytedependent anhydrite formation process is also supported by the finding of May et al. (2019) in other parts of the hyperarid Atacama Desert, where gypsum dominates at the surface and anhydrite in the subsurface accompanied by halite and nitratine. Hence, in the Atacama Desert, the presence of anhydrite is indirectly linked to the ambient aridity mediated through the accumulation of nitrates and chlorides in these hillslope soils, which only occurs under hyperarid conditions.

\subsection{Soil habitability \& Mars analogy}

It is essential to understand the role that water played in assessing the habitability, which can be studied using stable isotope and mineralogical proxies. In the last two decades the habitability of the hyperarid Atacama Desert has been studied intensively showing the presence of islands of microbial communities, so-called microhabitats (e.g., Warren-Rhodes et al., 2006; Davila \& Schulze-Makuch et al., 2016; Huang et al., 2020; Schulze-Makuch et al., 2021). Microhabitats near the soil surface such as hypolithic microenvironments retaining morning dew (Warren-Rhodes et al., 2006) and salt nodules attracting water vapor through hygroscopic effects, are closely linked to the ambient conditions. Schulze-Makuch et al. (2018) could show for the first-time microbial activity within the chusca horizon (in $20-30 \mathrm{~cm}$ depth) after a rain event. More challenging is the assessment of even deeper and highly cemented subsurface microenvironments where habitability is influenced by numerous and partially difficult to measure soil properties, like pore space, substrate composition, and salt concentrations at small spatial scales, in addition to water activity. Hence, if microbial activity occurs it can affect soil processes. Recent studies suggest that the plant Helianthemum squamatum common in Mediterranean climate (Palacio et al., 2014), and cyanobacteria collected from the Atacama Desert (Huang et al., 2020) are able to induce the liberation of the crystal water from gypsum, perhaps for their own usage. Microbial activity is likely also affecting stable isotope ratios as indicated by a soil 
436 phosphate study conducted in the Atacama Desert, which suggests that the $\delta^{18} \mathrm{O}$ isotope ratio of phosphates

437 can be used as a long-term proxy for microbial activity. Microbes shift the phosphate pool of the Atacama

438 Desert soil from an authigenic bedrock to a biogenic dominated pool and thereby incorporate the $\delta^{18} \mathrm{O}$ of the

439 rainwater in the phosphates. However, this proxy seems to be limited to regions with $>10$ mm of annual water

440 precipitation (Shen et al., 2020). In addition, the same study provided indications for microorganisms making

441 use of the gypsum hydration water, as the phosphate $\delta^{18} \mathrm{O}$ values were higher than the theoretical meteoric

442 water values, which could be explained by the fractionation of water $\delta^{18} \mathrm{O}$ during hydration of anhydrite to

443 gypsum. Hence, it cannot be ruled out that such biologically mediated anhydrite formation also played a role

444 in the past during more humid episodes in the here studied soils and perhaps still does.

445 Mars used to be home to rivers and lakes but transitioned early in its natural history into a hyperarid and cold 446 planet (Schulze-Makuch and Irwin, 2018). During this desertification process, vast amounts of sulfates were 447 deposited, which have been detected globally by satellite-based remote sensing (e.g., Murchie et al., 2009;

448 Wray et al., 2010) and in-situ by the Curiosity Rover in various hydration phases (gypsum, bassanite, 449 anhydrite) (Vaniman et al., 2018). Their formation has been proposed to have occurred at low temperatures $450 \quad\left(<50^{\circ} \mathrm{C}\right)$ in presence of highly soluble salts causing incomplete hydration during precipitation, which are very 451 similar conditions acting on the here investigated soils in the Atacama Desert. Beyond using sulfate hydration 452 phases as an aridity proxy, the hydration and dehydration of sulfate minerals could have served as a water reservoir for putative Martian subsurface microorganisms and may still do so. Therefore, further investigations

454 are warranted on the usage of crystal water for microbes in analog environments and ultimately on Mars. 
456 The soils along the elevation transect within the hyperarid Yungay valley, Atacama Desert, show depth-related 457 salt separation and measured as well as modeled sulfate $\delta^{34} \mathrm{~S}$ and $\delta^{18} \mathrm{O}$ distribution, indicating a common water458 soil interaction of incomplete salt transport by infiltrating rainwater. However, the degree of soil development 459 and the amount of soluble salts decrease with elevation, which could be a result of a higher erosion-rate with 460 elevation controlled by steeper slopes or a change of salt input within the study area. This is also supported by 461 the isotopic data we obtained. The investigated anhydrite occurrences at shallow depth are presumably a result 462 of rainwater, which can remain in the soil for months, followed by slow precipitation in the shallow moist soil 463 heated by solar radiation. Due to the lack of high temperatures at depth anhydrite can only form if highly 464 soluble salts such as nitrates or chlorides are present. Hence, our findings are important for correctly applying 465 the geochemical proxies for long-term environmental conditions and habitability of extremely dry soils on 466 Earth and also for extraterrestrial analogs.

\section{ACKNOWLEDGMENTS}

The authors acknowledge the support by the European Research Council Advanced Grant Habitability Of Martian Environments (339231), which provided base funding for the study, including sample collection and laboratory analysis. Thanks to Bernardita Valenzuela and Pedro Zamarano for helping to organizing the field work. We want to thank the Mineralogy Department of the Freie Universität Berlin for providing us access to the XRD-laboratory.

\section{REFERENCES}

Amundson, R., Barnes, J.D., Ewing, S., Heimsath, A., Chong, G., 2012. The stable isotope composition of halite and sulfate of hyperarid soils and its relation to aqueous transport. Geochimica et Cosmochimica Acta 99, 271-286.

Anderson, K., Wells, S., Graham, R., 2002. Pedogenesis of vesicular horizons, Cima volcanic field, Mojave

Artieda, O., Davila, A., Wierzchos, J., Buhler, P., Rodríguez-Ochoa, R., Pueyo, J., Ascaso, C., 2015. Surface evolution of salt-encrusted playas under extreme and continued dryness. Earth Surf. Process. Landforms 40, 1939-1950. 
Azua-Bustos, A., Fairén, A.G., González-Silva, C., Ascaso, C., Carrizo, D., Fernández-Martínez, M.Á., Fernández-Sampedro, M., García-Descalzo, L., García-Villadangos, M., Martin-Redondo, M.P., Sánchez-García, L., Wierzchos, J., Parro, V., 2018. Unprecedented rains decimate surface microbial communities in the hyperarid core of the Atacama Desert. Scientific reports 8, 16706.

Azua-Bustos, A., González-Silva, C., Corsini, G., 2017. The hyperarid core of the Atacama Desert, an extremely dry and carbon deprived habitat of potential interest for the field of carbon science. Frontiers in microbiology 8,993 .

Bozkurt, D., Rondanelli, R., Garreaud, R., Arriagada, A., 2016. Impact of warmer eastern tropical Pacific SST on the March 2015 Atacama floods. Monthly Weather Review 144, 4441-4460.

Cereceda, P., Larrain, H., Osses, P., Farías, M., Egaña, I., 2008. The spatial and temporal variability of fog and its relation to fog oases in the Atacama Desert, Chile. Atmospheric Research 87, 312-323.

Charola, A.E., Pühringer, J., Steiger, M., 2007. Gypsum: a review of its role in the deterioration of building materials. Environ Geol 52, 339-352.

Criss, R.E., 1999. Principles of stable isotope distribution. Oxford University Press on Demand.

Davila, A.F., Schulze-Makuch, D., 2016. The last possible outposts for life on Mars. Astrobiology 16, 159168.

Ericksen, G.E., 1981. Geology and origin of nitrate deposition in Atacama Desert. Geological Survey Professional Paper 1188.

Ewing, S.A., Michalski, G., Thiemens, M., Quinn, R.C., Macalady, J.L., Kohl, S., Wankel, S.D., Kendall, C., McKay, C.P., Amundson, R., 2007. Rainfall limit of the N cycle on Earth. Global Biogeochem. Cycles $21,1-12$

Ewing, S.A., Sutter, B., Owen, J., Nishiizumi, K., Sharp, W., Cliff, S.S., Perry, K., Dietrich, W., McKay, C.P., Amundson, R., 2006. A threshold in soil formation at Earth’s arid-hyperarid transition. Geochimica et Cosmochimica Acta 70, 5293-5322.

Ewing, S.A., Yang, W., DePaolo, D.J., Michalski, G., Kendall, C., Stewart, B.W., Thiemens, M., Amundson, R., 2008. Non-biological fractionation of stable Ca isotopes in soils of the Atacama Desert, Chile. Geochimica et Cosmochimica Acta 72, 1096-1110. 

Geoderma 284, 57-72.

Freyer, D., Voigt, W., 2003. Crystallization and phase stability of CaSO 4 and CaSO 4 - based salts. Monatshefte für Chemie / Chemical Monthly 134, 693-719.

Hardie, A.L., 1967. The gypsum-anhydrite equilibrium at one atmosphere pressure. American Mineralogist $52,171-200$.

Houston, J., Hartley, A.J., 2003. The central Andean west-slope rainshadow and its potential contribution to the origin of hyper-aridity in the Atacama Desert. Int. J. Climatol. 23, 1453-1464.

Huang, W., Ertekin, E., Wang, T., Cruz, L., Dailey, M., DiRuggiero, J., Kisailus, D., 2020. Mechanism of water extraction from gypsum rock by desert colonizing microorganisms. Proceedings of the National

Jordan, T., Riquelme, R., González, G., Herrera, C., Godfrey, L., Colucci, S., Gironás-León, J., Gamboa, C., Urrutia, J., Tapia, L., others, 2015. Hydrological and geomorphological consequences of the extreme precipitation event of 24-26 March 2015, Chile, in: XIV Congreso Geológico de Chile.

Jordan, T.E., Kirk-Lawlor, N.E., Blanco, N.P., Rech, J.A., Cosentino, N.J., 2014. Landscape modification in response to repeated onset of hyperarid paleoclimate states since $14 \mathrm{Ma}$, Atacama Desert, Chile.

Jordan, T.E., Lohman, R.B., Tapia, L., Pfeiffer, M., Scott, C.P., Amundson, R., Godfrey, L., Riquelme, R., 
McKay, C.P., Friedmann, E.I., Gómez-Silva, B., Cáceres-Villanueva, L., Andersen, D.T., Landheim, R., 2003. Temperature and Moisture Conditions for Life in the Extreme Arid Region of the Atacama Desert: Four Years of Observations Including the El Niño of 1997-1998. Astrobiology.

Michalski, G., Böhlke, J.K., Thiemens, M., 2004. Long term atmospheric deposition as the source of nitrate and other salts in the Atacama Desert, Chile: New evidence from mass-independent oxygen isotopic compositions. Geochimica et Cosmochimica Acta 68, 4023-4038.

Murchie, S.L., Mustard, J.F., Ehlmann, B.L., Milliken, R.E., Bishop, J.L., McKeown, N.K., Noe Dobrea, E.Z., Seelos, F.P., Buczkowski, D.L., Wiseman, S.M., Arvidson, R.E., Wray, J.J., Swayze, G., Clark, R.N., Des Marais, D.J., McEwen, A.S., Bibring, J.-P., 2009. A synthesis of Martian aqueous mineralogy after 1 Mars year of observations from the Mars Reconnaissance Orbiter. J. Geophys. Res. 114, 711.

Owen, J.J., Dietrich, W.E., Nishiizumi, K., Chong, G., Amundson, R., 2013. Zebra stripes in the Atacama Desert: Fossil evidence of overland flow. Geomorphology 182, 157-172.

Palacio, S., Azorín, J., Montserrat-Martí, G., Ferrio, J.P., 2014. The crystallization water of gypsum rocks is a relevant water source for plants. Nature communications 5, 4660 .

Pérez-Fodich, A., Reich, M., Álvarez, F., Snyder, G.T., Schoenberg, R., Vargas, G., Muramatsu, Y., Fehn, U., 2014. Climate change and tectonic uplift triggered the formation of the Atacama Desert's giant nitrate deposits. Geology 42, 251-254.

Pfeiffer, M., Morgan, A., Heimsath, A., Jordan, T., Howard, A., Amundson, R., 2021. Century scale rainfall in the absolute Atacama Desert: Landscape response and implications for past and future rainfall. Quaternary Science Reviews 254, 106797.

Placzek, C.J., Matmon, A., Granger, D.E., Quade, J., Niedermann, S., 2010. Evidence for active landscape evolution in the hyperarid Atacama from multiple terrestrial cosmogenic nuclides. Earth and Planetary Science Letters 295, 12-20.

Quade, J., Reiners, P., Placzek, C., Matmon, A., Pepper, M., Ojha, L., Murray, K., 2012. Seismicity and the strange rubbing boulders of the Atacama Desert, northern Chile. Geology 40, 851-854.

Rech, J.A., Quade, J., Hart, W.S., 2003. Isotopic evidence for the source of Ca and S in soil gypsum, anhydrite and calcite in the Atacama Desert, Chile. Geochimica et Cosmochimica Acta 67, 575-586. 

phases. Global and Planetary Change 187, 103132.

Sager, C., Airo, A., Arens, F.L., Rabethge, C., Schulze-Makuch, D., 2020. New types of boulder accumulations in the hyper-arid Atacama Desert. Geomorphology 350, 106897.

Sager, C., Airo, A., Arens, F.L., Schulze-Makuch, D., 2021. New type of sand wedge polygons in the salt cemented soils of the hyper-arid Atacama Desert. Geomorphology 373, 107481

Schulze-Makuch, D., Irwin, L.N., 2018. Life in the Universe: Expectations and Constraints, 3rd ed. Springer International Publishing, Cham, 343 pp.

Schulze-Makuch, D., Wagner, D., Kounaves, S.P., Mangelsdorf, K., Devine, K.G., Vera, J.-P. de, Schmitt-

Seufert, S., Hesse, C., Götz-Neunhoeffer, F., Neubauer, J., 2009. Discrimination of bassanite and anhydrite Kopplin, P., Grossart, H.-P., Parro, V., Kaupenjohann, M., Galy, A., Schneider, B., Airo, A., Frösler, J., Davila, A.F., Arens, F.L., Cáceres, L., Cornejo, F.S., Carrizo, D., Dartnell, L., DiRuggiero, J., Flury, M., Ganzert, L., Gessner, M.O., Grathwohl, P., Guan, L., Heinz, J., Hess, M., Keppler, F., Maus, D., McKay, C.P., Meckenstock, R.U., Montgomery, W., Oberlin, E.A., Probst, A.J., Sáenz, J.S., Sattler, T., Schirmack, J., Sephton, M.A., Schloter, M., Uhl, J., Valenzuela, B., Vestergaard, G., Wörmer, L., Zamorano, P., 2018. Transitory microbial habitat in the hyperarid Atacama Desert. Proceedings of the National Academy of Sciences of the United States of America 115, 2670-2675.

Schulze-Makuch, D., Lipus, D., Arens, F.L., Baqué, M., Bornemann, T.L.V., deVera, JP., Flury, M., Frösler, J., Heinz, J., Hwang, Y., Kounaves, S.P., Kai Mangelsdorf11, Meckenstock, R.U., Pannekens, M., Probst, A.J., Sáenz J.S., Schirmack, J., Schloter, M., Schmitt-Kopplin, P., Schneider, B., Uhl, J., Vestergaard, G., Valenzuela, B., Zamorano, P., Wagner, D. 2021. Lithic Microhabitats and Microbial hotspots in the Atacama Desert inferred from DNA fractionation and metagenomics. Microorganisms 9, 1038.

Seal, R.R., Alpers, C.N., Rye, R.O., 2000. Stable isotope systematics of sulfate minerals. Reviews in Mineralogy and Geochemistry 40, 541-602. III dehydrated from gypsum at different temperatures. Zeitschrift für Kristallographie, Supplement Suppl. 30, 447-452. 
Shen, J., Smith, A.C., Claire, M.W., Zerkle, A.L., 2020. Unraveling biogeochemical phosphorus dynamics in hyperarid Mars-analogue soils using stable oxygen isotopes in phosphate. Geobiology 18, 760-779.

Sutter, B., Dalton, J.B., Ewing, S.A., Amundson, R., McKay, C.P., et al., 2007. Terrestrial analogs for interpretation of infrared spectra from the Martian surface and subsurface: Sulfate, nitrate, carbonate, and phyllosilicate-bearing Atacama Desert soils. Journal of Geophysical Research 112.

van Driessche, A.E.S., Canals, A., Ossorio, M., Reyes, R.C., Garcia-Ruiz, J.M., 2016. Unraveling the sulfate sources of (giant) gypsum crystals using gypsum isotope fractionation factors. The Journal of Geology $124,235-245$.

Vaniman, D.T., Martínez, G.M., Rampe, E.B., Bristow, T.F., Blake, D.F., Yen, A.S., Ming, D.W., Rapin, W., Meslin, P.-Y., Morookian, J.M., Downs, R.T., Chipera, S.J., Morris, R.V., Morrison, S.M., Treiman, A.H., Achilles, C.N., Robertson, K., Grotzinger, J.P., Hazen, R.M., Wiens, R.C., Sumner, D.Y., 2018. Gypsum, bassanite, and anhydrite at Gale crater, Mars. American Mineralogist 103, 1011-1020.

Voigt, C., Klipsch, S., Herwartz, D., Chong, G., Staubwasser, M., 2020. The spatial distribution of soluble salts in the surface soil of the Atacama Desert and their relationship to hyperaridity. Global and Planetary Change 184, 103077.

Warren-Rhodes, K.A., Rhodes, K.L., Pointing, S.B., Ewing, S.A., Lacap, D.C., Gómez-Silva, B., Amundson, R., Friedmann, E.I., McKay, C.P., 2006. Hypolithic cyanobacteria, dry limit of photosynthesis, and microbial ecology in the hyperarid Atacama Desert. Microbial ecology, 389-398.

Wilhelm, M.B., Davila, A.F., Eigenbrode, E.S., Parenteau, M.N., Liu, X., Summons, R.E., Wray, J.J., Stamos, B.N., O`Reilly, S.S., Williams, A., 2017. Xeropreservation of functionalized lipid biomarkers in hyperarid soils in the Atacama Desert. Organic Chemistry 103.

Wilson, M.A., Shahid, S.A., Abdelfattah, M.A., Kelley, J.A., Thomas, J.E., 2012. Anhydrite Formation on the Coastal Sabkha of Abu Dhabi, United Arab Emirates. In: Shahid, S.A., Taha, F.K., Abdelfattah, M.A. (Eds.) Developments in Soil Classification, Land Use Planning and Policy Implications. Innovative Thinking of Soil Inventory for Land Use Planning and Management of Land Resources. Springer, Dordrecht, pp. 175-201.

Wray, J.J., Squyres, S.W., Roach, L.H., Bishop, J.L., Mustard, J.F., Noe Dobrea, E.Z., 2010. Identification of the Ca-sulfate bassanite in Mawrth Vallis, Mars. Icarus 209, 416-421. 
618 Zeebe, R.E., 2010. A new value for the stable oxygen isotope fractionation between dissolved sulfate ion and 619 water. Geochimica et Cosmochimica Acta 74, 818-828. 


\section{Supplements}

for

Geochemical proxies for water-soil interactions in the hyperarid Atacama Desert, Chile 


\begin{tabular}{|c|c|c|c|c|c|c|c|c|c|}
\hline \multirow{3}{*}{$\begin{array}{c}\text { Soil } \\
\text { profile }\end{array}$} & \multicolumn{4}{|c|}{ Location } & \multicolumn{2}{|c|}{ Weighted average values } & \multicolumn{3}{|c|}{ Total salt inventory } \\
\hline & Longitude & Latitude & Elevation & Slope & $\delta^{34} \mathrm{~S}_{\mathrm{VCDT}}$ & $\delta^{18} \mathrm{O}_{\text {SMOW }}$ & $\mathrm{SO}_{4}{ }^{2-}$ & $\mathrm{Cl}^{-}$ & $\mathrm{NO}_{3}^{-}$ \\
\hline & \multicolumn{2}{|c|}{ [WGS84] } & [m a.s.l.] & {$\left[{ }^{\circ}\right]$} & {$[\% 0]$} & {$[\%]$} & & {$\left[\mathrm{kg} \mathrm{m}^{-2}\right.$} & \\
\hline $\mathrm{HP}$ & $24^{\circ} 03^{\prime} 47^{\prime \prime} \mathrm{S}$ & $70^{\circ} 01^{\prime} 06^{\prime \prime} \mathrm{W}$ & 1436 & 8 & 7.6 & 3.0 & 256 & 0.04 & 0.18 \\
\hline $\mathrm{HM}$ & $24^{\circ} 04^{\prime} 17^{\prime \prime S}$ & $70^{\circ} 03^{\prime} 08^{\prime \prime} \mathrm{W}$ & 1217 & 6 & 6.8 & 2.0 & 325 & 2.45 & 0.37 \\
\hline HD & $24^{\circ} 05^{\prime} 18^{\prime \prime} \mathrm{S}$ & $69^{\circ} 59^{\prime} 40^{\prime \prime} \mathrm{W}$ & 1005 & 2 & 5.3 & 5.5 & 395 & 5.99 & 7.64 \\
\hline $\mathrm{TD}$ & $24^{\circ} 06^{\prime} 06^{\prime \prime} \mathrm{S}$ & $70^{\circ} 01^{\prime} 06^{\prime \prime} \mathrm{W}$ & 1021 & 1 & $3.7^{\mathrm{a}}$ & $7.5^{\mathrm{a}}$ & $240^{\mathrm{b}}$ & $62.9^{b}$ & $6.47^{b}$ \\
\hline
\end{tabular}

${ }^{a}$ value based on data from Ewing et al., (2008)

${ }^{b}$ for total salt inventory of TD only values $<140 \mathrm{~cm}$ depth are considered.

Table S2 All quantified analytical results

\begin{tabular}{|c|c|c|c|c|c|c|c|c|c|}
\hline Sample & $\begin{array}{c}\text { Sample } \\
\text { interval } \\
{[\mathrm{cm}]}\end{array}$ & $\begin{array}{c}\delta^{34} \mathrm{~S}^{\mathrm{a}} \\
\text { measured }\end{array}$ & $\begin{array}{c}\delta^{34} \mathrm{~S} \\
\text { modeled }\end{array}$ & $\begin{array}{c}\delta^{18} \mathrm{O}^{\mathrm{b}} \\
\text { measured } \\
{[\% \mathrm{o}]}\end{array}$ & $\begin{array}{c}\delta^{18} \mathrm{O} \\
\text { modeled }\end{array}$ & $\mathrm{SO}_{4}^{2-\mathrm{c}}$ & $\begin{array}{c}\mathrm{Cl}^{-\mathrm{c}} \\
{\left[\mathrm{mg} \mathrm{g}^{-1}\right]}\end{array}$ & $\mathrm{NO}_{3}^{-\mathrm{c}}$ & $\begin{array}{c}\text { Soluble } \\
\text { content }^{\mathrm{d}} \\
{[\mathrm{wt} \%]}\end{array}$ \\
\hline & \multicolumn{9}{|c|}{ Herradura Proximal (HP) } \\
\hline HP-0 & $0-5$ & 12.1 & 9.6 & 11.0 & 6.3 & 28.4 & 0.0 & 0.0 & 10 \\
\hline HP-10 & $5-15$ & 9.6 & 9.3 & 6.2 & 5.8 & 582 & 0.0 & 0.0 & 83 \\
\hline HP-20 & $15-25$ & 9.1 & 8.8 & 6.5 & 5.1 & 357 & 0.0 & 0.0 & 49 \\
\hline HP-30 & $25-35$ & 7.0 & 8.4 & 2.9 & 3.8 & 357 & 0.0 & 0.3 & 46 \\
\hline HP-40 & $35-45$ & 6.8 & 7.7 & & & 276 & 0.0 & 0.2 & 34 \\
\hline HP-50 & $45-55$ & & & & & 275 & 0.0 & 0.1 & 32 \\
\hline HP-60 & $55-65$ & 5.9 & 6.1 & -0.7 & 0.8 & 436 & 0.0 & 0.2 & 54 \\
\hline HP-70 & $65-75$ & & & & & 130 & 0.0 & 0.3 & 15 \\
\hline HP-80 & $75-85$ & 5.8 & 3.1 & -1.0 & -4.5 & 96.6 & 0.3 & 0.4 & 5 \\
\hline \multirow[t]{2}{*}{ HP-90 } & $85-95$ & 6.5 & -1.0 & 1.0 & -11.3 & 67.3 & 0.2 & 0.4 & 12 \\
\hline & \multicolumn{9}{|c|}{ Herradura Medial (HM) } \\
\hline HM-0 & $0-2.5$ & 10.2 & 8.8 & 9.3 & 5.3 & 0.25 & 0.00 & 0.00 & 2 \\
\hline HM-5 & $2.5-7.5$ & 8.3 & 8.8 & 5.6 & 5.3 & & & & \\
\hline HM-10 & $7.5-15$ & 8.0 & 8.8 & 3.8 & 5.3 & 0.19 & 0.00 & 0.00 & 1 \\
\hline HM-20 & $15-25$ & 8.7 & 8.7 & 5.1 & 5.1 & 324 & 0.00 & 0.00 & 50 \\
\hline HM-30 & $25-35$ & 7.7 & 8.5 & 3.7 & 4.7 & 405 & 0.00 & 0.00 & 52 \\
\hline HM-40 & $35-45$ & 6.4 & 8.0 & 1.1 & 4.0 & 410 & 0.00 & 0.00 & 54 \\
\hline HM-50 & $45-55$ & & & & & 394 & 0.00 & 0.00 & 53 \\
\hline HM-60 & $55-65$ & 6.1 & 7.2 & 0.4 & 2.5 & 518 & 0.00 & 0.00 & 54 \\
\hline HM-70 & $65-75$ & & & & & 425 & 0.33 & 0.00 & 39 \\
\hline HM-80 & $75-85$ & 6.8 & 5.2 & 2.2 & -0.7 & 423 & 3.38 & 0.95 & 33 \\
\hline HM-90 & $85-95$ & & & & & 343 & 20.8 & 2.73 & 50 \\
\hline \multirow[t]{2}{*}{ HМ-100 } & $95-105$ & 6.6 & 1.0 & 1.9 & -7.5 & 18.8 & 0.07 & 0.00 & 6 \\
\hline & \multicolumn{9}{|c|}{ Herradura Distal (HD) } \\
\hline HD-0 & $0-2.5$ & 8.0 & 7.3 & 9.7 & 8.8 & 26.2 & 0.00 & 0.00 & 1 \\
\hline HD-5 & $2.5-7.5$ & 7.8 & 7.2 & 8.6 & 8.7 & 539 & 0.00 & 0.00 & 79 \\
\hline HD-10 & $7.5-15$ & 6.5 & 7.1 & 6.3 & 8.4 & 509 & 0.00 & 0.00 & 84 \\
\hline HD-20 & $15-25$ & 5.3 & 6.8 & 4.7 & 8.1 & 388 & 0.00 & 0.00 & 71 \\
\hline HD-30 & $25-35$ & 6.0 & 6.6 & 5.9 & 7.6 & 416 & 0.00 & 0.00 & 74 \\
\hline HD-40 & $35-45$ & 4.3 & 6.0 & 2.8 & 6.8 & 556 & 0.11 & 0.08 & 82 \\
\hline HD-50 & $45-55$ & & & & & 447 & 1.57 & 0.57 & 68 \\
\hline HD-60 & $55-65$ & 5.1 & 5.4 & 5.7 & 5.7 & 70.6 & 3.30 & 2.46 & 16 \\
\hline HD-70 & $65-75$ & & & & & 84.8 & 3.95 & 1.78 & 19 \\
\hline
\end{tabular}




\begin{tabular}{|c|c|c|c|c|c|c|c|c|c|}
\hline Sample & $\begin{array}{c}\text { Sample } \\
\text { interval } \\
{[\mathrm{cm}]}\end{array}$ & $\begin{array}{c}\delta^{34} S^{a} \\
\text { measured }\end{array}$ & $\begin{array}{c}\delta^{34} \mathrm{~S} \\
\text { modeled }\end{array}$ & $\begin{array}{c}\delta^{18} \mathrm{O}^{\mathrm{b}} \\
\text { measured } \\
{[\% \mathrm{o}]}\end{array}$ & $\begin{array}{c}\delta^{18} \mathrm{O} \\
\text { modeled }\end{array}$ & $\mathrm{SO}_{4}^{2-\mathrm{c}}$ & $\begin{array}{c}\mathrm{Cl}^{-\mathrm{c}} \\
{\left[\mathrm{mg} \mathrm{g}^{-1}\right]}\end{array}$ & $\mathrm{NO}_{3}^{-\mathrm{c}}$ & $\begin{array}{c}\text { Soluble } \\
\text { content }^{\mathrm{d}} \\
{[\mathrm{wt} \%]}\end{array}$ \\
\hline HD-80 & $75-85$ & 5.2 & 5.0 & 5.5 & 5.1 & 114 & 5.56 & 1.99 & 18 \\
\hline HD-90 & $85-95$ & & & & & 54.7 & 1.89 & 1.41 & 11 \\
\hline HD-100 & $95-105$ & 5.1 & 4.6 & 6.1 & 4.5 & 59.4 & 2.31 & 2.63 & 15 \\
\hline HD-110 & $105-115$ & & & & & 273 & 2.49 & 2.77 & 42 \\
\hline HD-120 & $115-125$ & 5.4 & 3.9 & 6.5 & 3.2 & 233 & 1.61 & 2.37 & 42 \\
\hline HD-130 & $125-135$ & & & & & 104 & 6.48 & 6.26 & 17 \\
\hline HD-140 & $135-145$ & 4.8 & 2.7 & 6.4 & 1.2 & 107 & 4.67 & 6.08 & 13 \\
\hline HD-150 & $145-155$ & & & & & 207 & 6.06 & 15.9 & 60 \\
\hline \multirow[t]{2}{*}{ HD-160 } & $155-165$ & 3.8 & -0.1 & 7.1 & -3.3 & 355 & 39.9 & 64.3 & 58 \\
\hline & \multicolumn{9}{|c|}{ Tetas Distal (TD) } \\
\hline TD-0 & $0-2.5$ & & & & & 6.98 & 0.00 & 0.00 & 4 \\
\hline$\underline{T D-1}$ & $\underline{0-2.5}$ & $\underline{9.6}$ & 5.7 & $\underline{13}$ & 10.8 & $\underline{77}$ & & & \\
\hline$\underline{T D-2.5}$ & $\underline{2-3}$ & $\underline{9.2}$ & 5.7 & $\underline{11}$ & 10.8 & $\underline{384}$ & & & \\
\hline TD-5 & $2.5-7.5$ & & & & & 686 & 0.00 & 0.00 & 61 \\
\hline$\underline{T D-7.5}$ & $\underline{3-12}$ & $\underline{6.9}$ & 5.6 & $\underline{10}$ & 10.6 & $\underline{240}$ & & & \\
\hline TD-10 & $7.5-15$ & & & & & 448 & 0.00 & 0.00 & 57 \\
\hline$\underline{T D-19}$ & $\underline{12-26}$ & $\underline{4}$ & 5.4 & $\underline{9}$ & 10.2 & $\underline{269}$ & & & \\
\hline TD-20 & $15-25$ & 4.3 & & 7.0 & & 211 & 0.00 & 0.00 & 46 \\
\hline TD-30 & $25-35$ & & & & & 326 & 0.00 & 0.00 & 27 \\
\hline$\underline{T D-32.5}$ & $26-39$ & $\underline{5}$ & 5 & $\underline{8}$ & 9.6 & $\underline{288}$ & & & \\
\hline TD-40 & $35-45$ & & & & & 248 & 0.75 & 0.34 & 34 \\
\hline TD-50 & $45-55$ & & & & & 142 & 4.67 & 1.62 & 25 \\
\hline$\underline{T D-55}$ & $\underline{39-71}$ & $\underline{4.3}$ & 4.2 & $\underline{7}$ & 8.3 & $\underline{221}$ & & & \\
\hline TD-60 & $55-65$ & & & & & 15 & 4.41 & 1.61 & 29 \\
\hline TD-70 & $65-75$ & & & & & 133 & 34.7 & 4.97 & 29 \\
\hline$\underline{T D-78.5}$ & $\underline{71-85}$ & $\underline{2.2}$ & 3.2 & $\underline{8}$ & 6.6 & $\underline{192}$ & & & \\
\hline TD-80 & $75-85$ & & & & & 63.7 & 8.69 & 3.77 & 13 \\
\hline TD-90 & $85-95$ & & & & & 93.6 & 9.29 & 12.6 & 27 \\
\hline$\underline{T D-94}$ & $\underline{85-102}$ & $\underline{1.4}$ & 2.2 & $\underline{5}$ & 4.9 & $\underline{182}$ & & & \\
\hline TD-100 & $95-105$ & & & & & 131 & 29.7 & 4.94 & 29 \\
\hline TD-110 & $105-115$ & & & & & 92.2 & 85.6 & 7.60 & 39 \\
\hline$\underline{T D-112}$ & $\underline{102-122}$ & $\underline{0.8}$ & -0.7 & $\underline{6}$ & 0.3 & $\underline{144}$ & & & \\
\hline TD-120 & $115-125$ & & & & & 79.6 & 7.75 & 12.3 & 22 \\
\hline TD-130 & $125-135$ & & & & & 17.2 & 438 & 9.94 & 81 \\
\hline TD-140 & $135-145$ & & & & & 57.3 & 8.22 & 10.2 & 17 \\
\hline TD-150 & $145-155$ & & & & & 57.8 & 5.43 & 10.4 & 20 \\
\hline TD-160 & $155-165$ & & & & & 57.2 & 2.69 & 3.75 & 18 \\
\hline TD-170 & $165-175$ & & & & & 29.3 & 1.40 & 1.36 & 15 \\
\hline TD-180 & $175-185$ & & & & & 50.2 & 2.45 & 3.40 & 18 \\
\hline TD-190 & $185-195$ & & & & & 60.4 & 1.88 & 4.43 & 21 \\
\hline TD-200 & $195-205$ & & & & & 51.6 & 3.06 & 4.86 & 17 \\
\hline \multicolumn{10}{|c|}{${ }^{\mathrm{a}}$ Uncertainty is $\pm 0.3 \%$ o } \\
\hline \multicolumn{10}{|c|}{ b Uncertainty is $\pm 0.6 \%$ o } \\
\hline \multicolumn{10}{|c|}{${ }^{\mathrm{c}}$ Uncertainty is $10 \%$} \\
\hline Uncertain & is $5 \%$ & & & & & & & & \\
\hline
\end{tabular}

Data \& values from Ewing et al. (2008) are in italic and underlined 

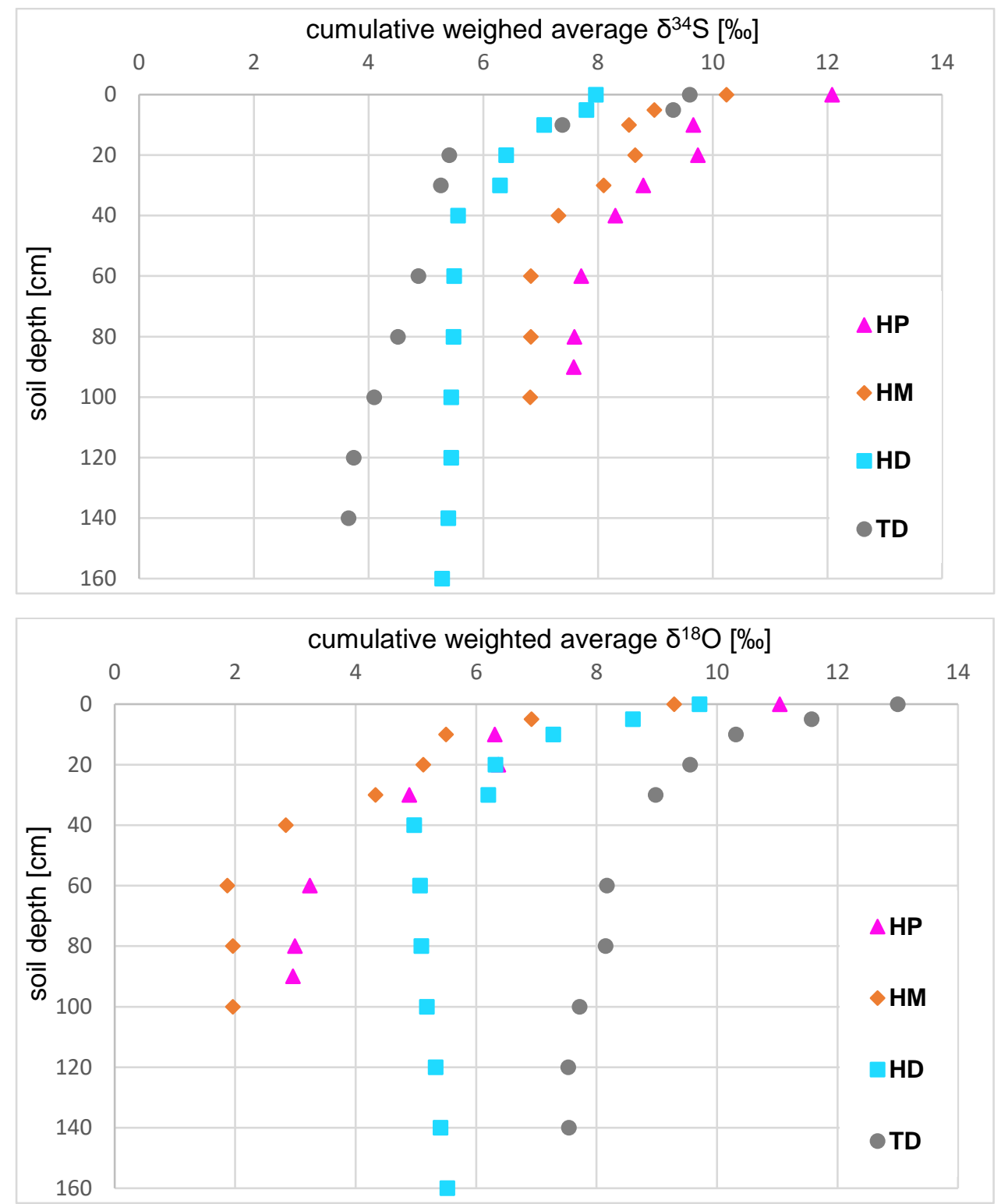

Figure S1 cumulative weighted average of $\delta^{34} S$ and $\delta^{18} O$ for each soil profile considering different maximum soil depth. 


\section{HERRADURA PROXIMAL}

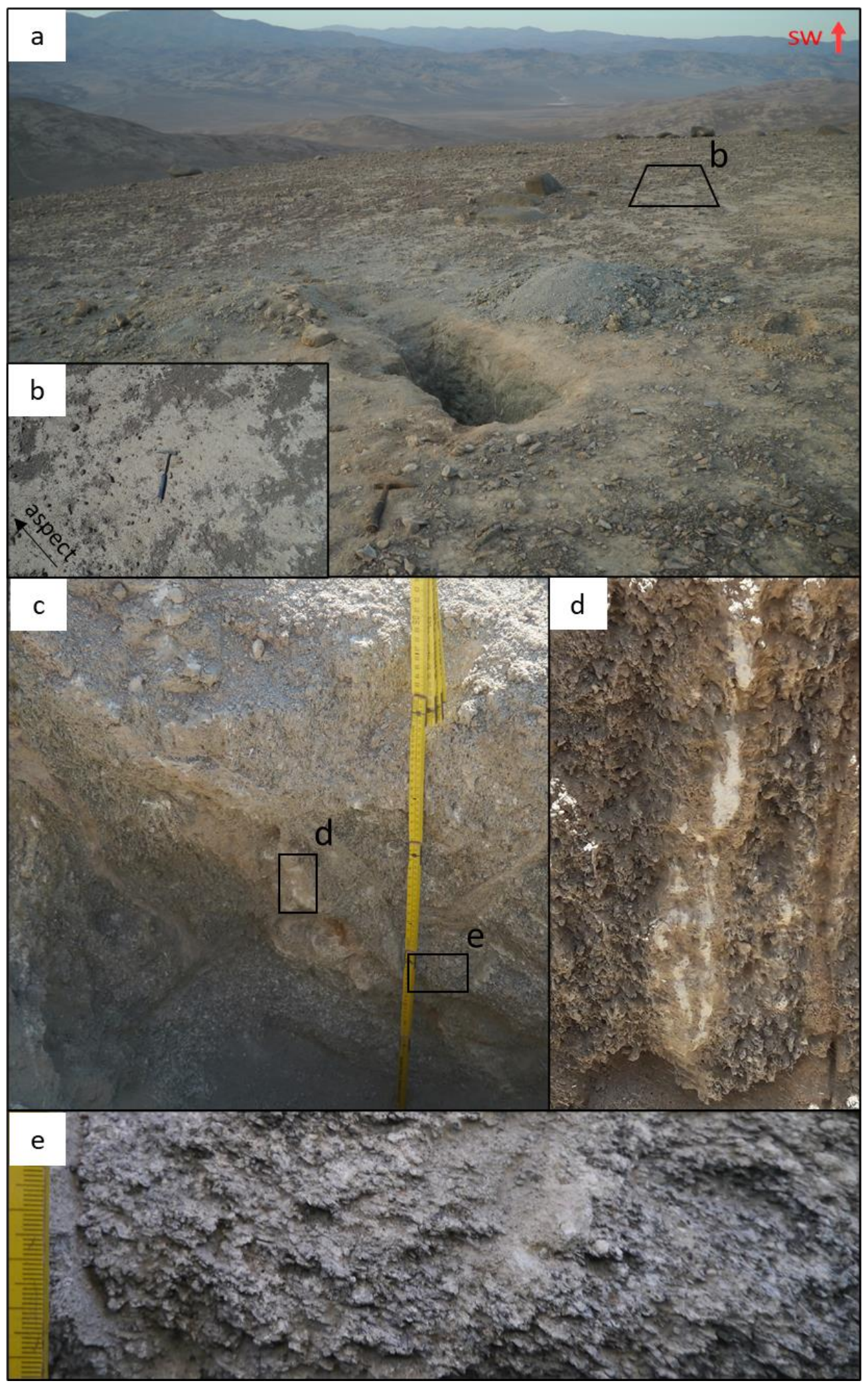

Figure S2 Herradura Proximal site. a) The pit is located near the crest of Cerro Herradura, in the vicinity weathered bedrock core-stones on the surface are present. b) Loose surface clasts, lying on a clay-rich crust, have sorted in hillslope-parallel bands, described by Owen et al. (2013) as a result of overland-flow or due to seismic shaking by May et al. (2019). c) Overview of the soil profile. Prominent filled crack/veins (d) cut through the matrix of fragmented bedrock (e). These veins are filled by salt (sulfate) and silicate dust. The bedrock, fragmented into clasts of few mm size, is coated in salt. 


\section{HERRADURA MEDIAL}

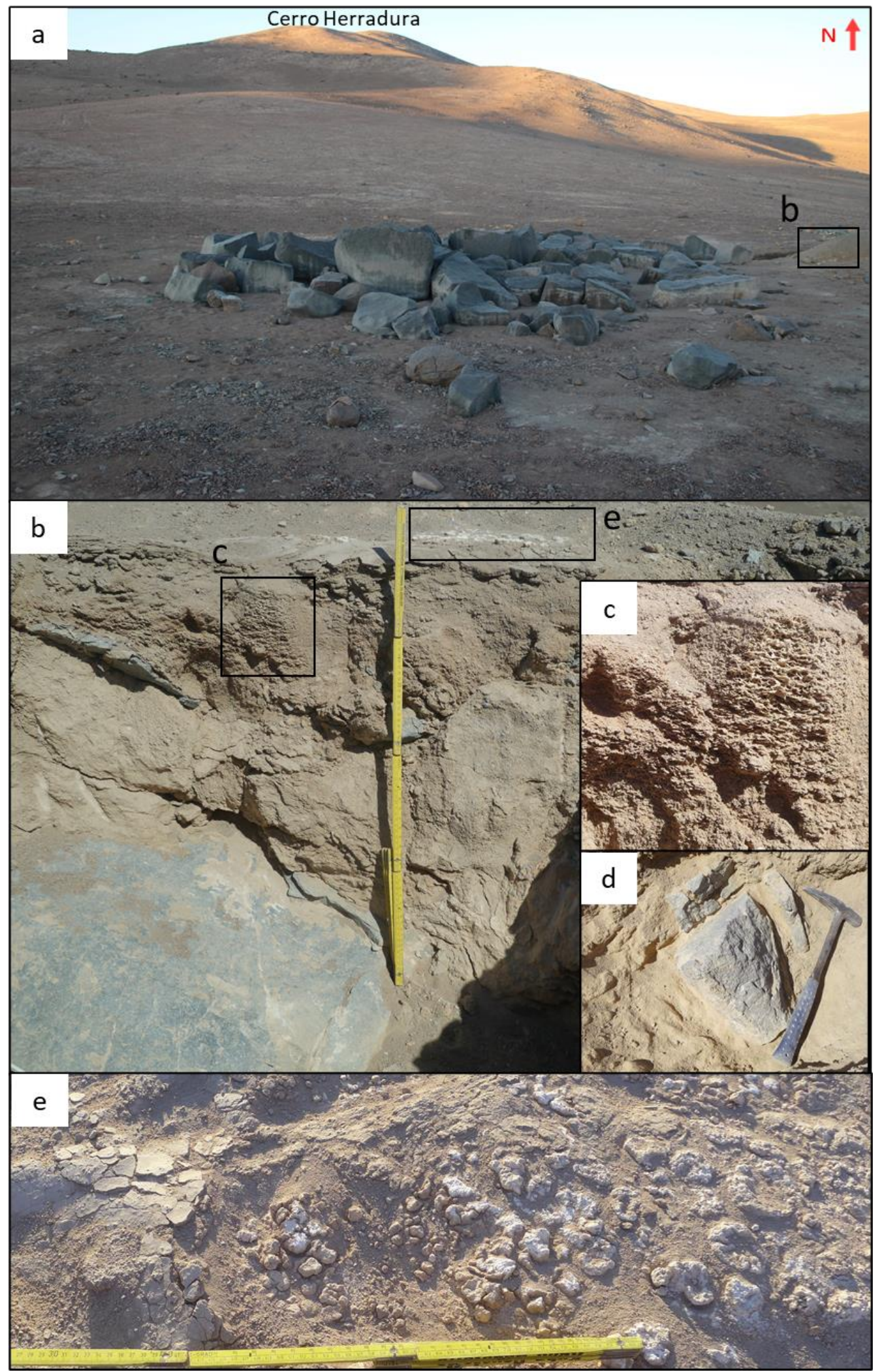

Figure S3 Herradura Medial site. a) The pit is located $1.4 \mathrm{~km}$ downslope of Cerro Herradura, near a boulder cluster (described by Sager et al. 2020). b) The soil profile is situated on an intrusive dyke, being more weathering resistant than the surrounding bedrock. The dyke material is fractured by salt $(d)$ and is floating in the soil matrix, which is highly cemented by sulfates. In the upper soil layer $(\sim 10-20 \mathrm{~cm}$ depth) lies the vesicular layer $(c)$ with its typical porous sponge-like texture. e) Above lies a weakly cemented clay-rich layer, covered by a desert pavement. In areas where the vesicular layer is close to the surface initial losas are present. 

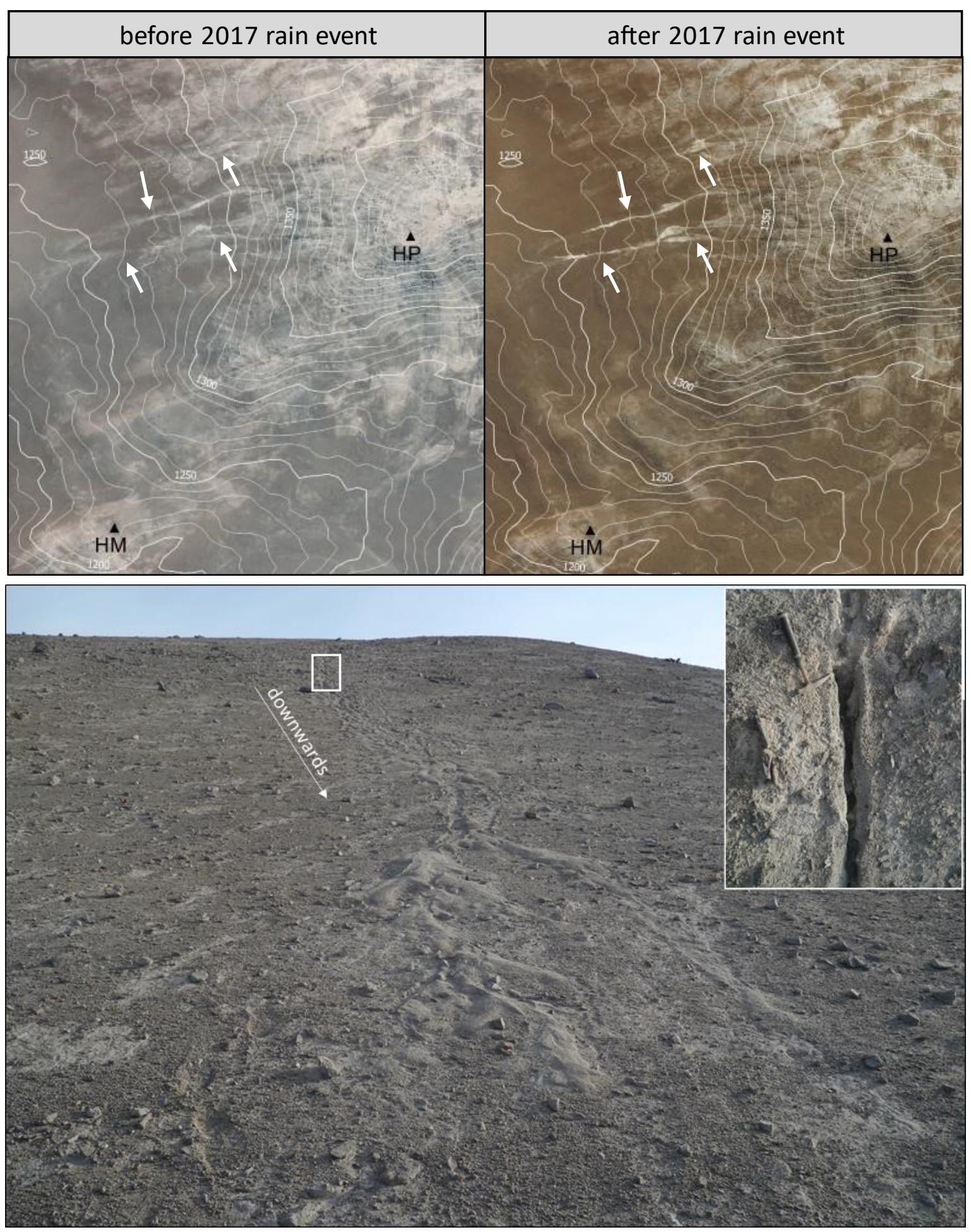

Figure S4 surface run-off tracks after the rain event in 2017 in the study area recorded by us and other research group e.g. Jordan et al. (2020). Upper two images are satellite data based (visual (from Bing Maps, Microsoft 2016 \& 2019) and STRM), showing the Cerro Herradura mountain with the two pits HP and HD and elevation contour lines. On the west slope fresh surface run-off channels are visible after the rain event, marked with white arrow. Lower image shows field observation of the run-off channel. Inlet image shows channel further upslope. 
HERRADURA DISTAL

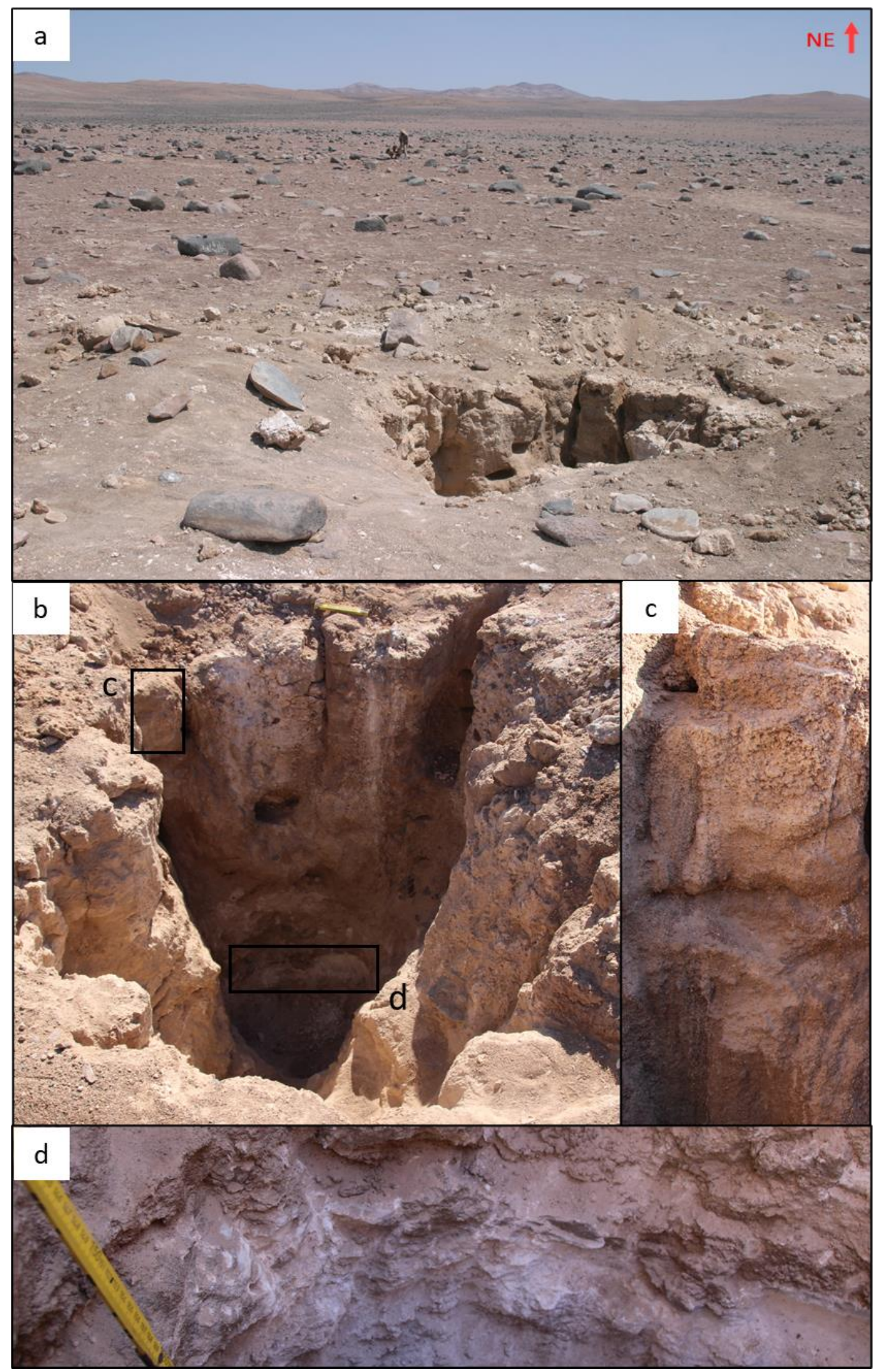

Figure S5 Herradura Distal site. a) The pit with surrounding alluvial fan area, covered with boulders. b) Overview of the soil column, separated by vertical layered sand-wedges (c). Well-developed chuca horizon (including vesicular layer) grading into costra with pebble- and cobble-size clasts floating is a firmly cemented fine-grain matrix. Due to the excavation the surface soil horizon (chuca) was removed on the opposing sidewall exposing the costra. In the base of the soil firmly cemented nitrate-rich caliche $(d)$ is present. 


\section{TETAS DISTAL}

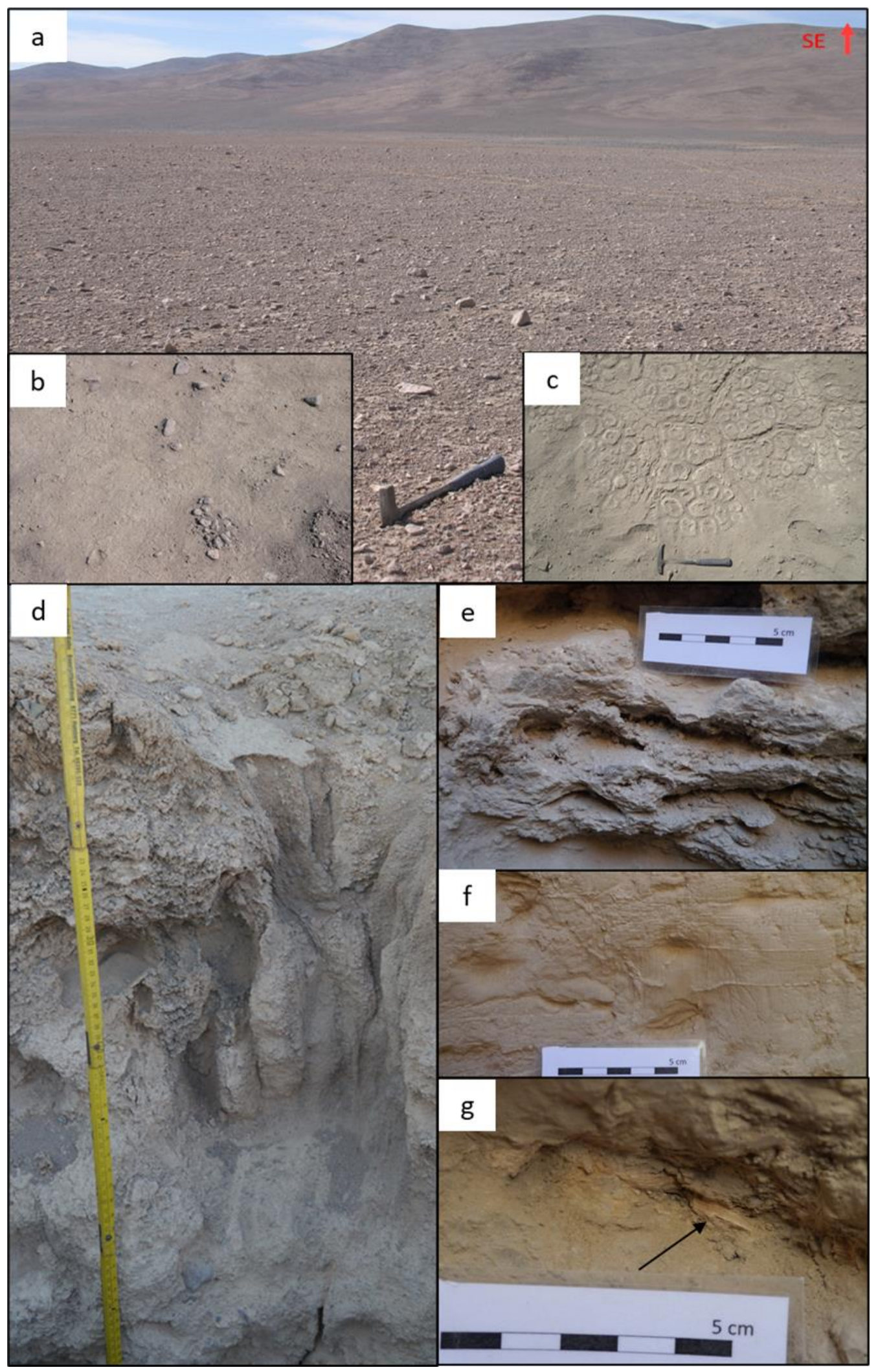

Figure S6 Tetas Distal site. a) It is located on the southern side of the valley with smooth alluvial fan, without boulder cover and a well-developed desert pavement. b) By removing the loose surface clasts, a clay-rich crust appears. c) When removing the clay crust the losa (Fig. S6) emerge in patches separated by sand-wedges. (d) Upper soil is similar to the Herradura Distal. With increasing soil depth, the maximum clasts-size decreases. At $130 \mathrm{~cm}$ depth a chloride-rich horizon with cavities is present. (f) Below silt and clay dominate the lithic fraction, deposited in fine layers, which are cut by a fine grid of salt veins. Within this matrix plant fragments $(g)$ are embedded. 


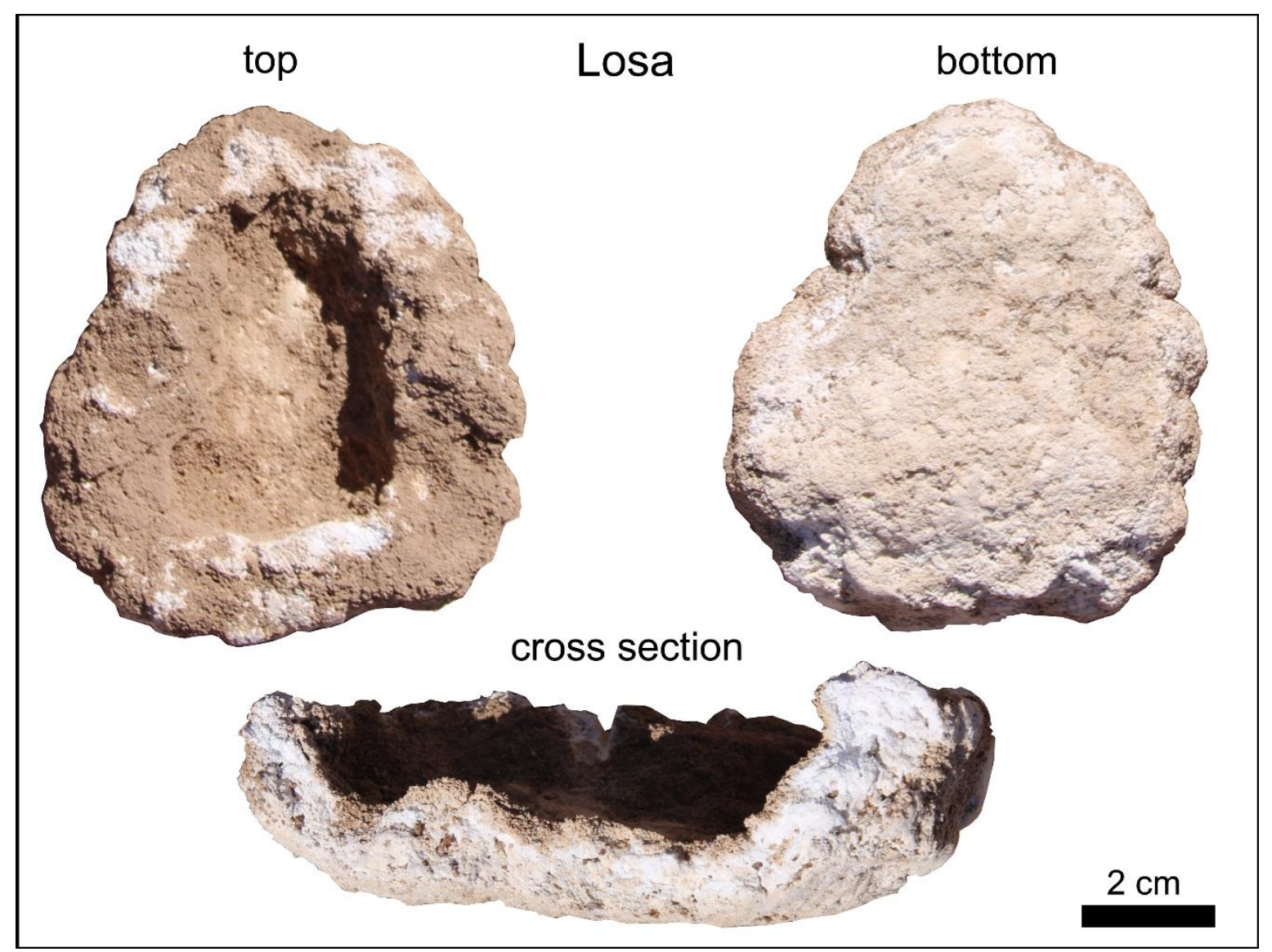

Figure S7 losa, bowl-shaped cakes. The two exemplars (1. in top \& bottom view and 2. in cross section view) were excavated near HD and the loose topsoil, consisting of sand and dust particles was removed. 


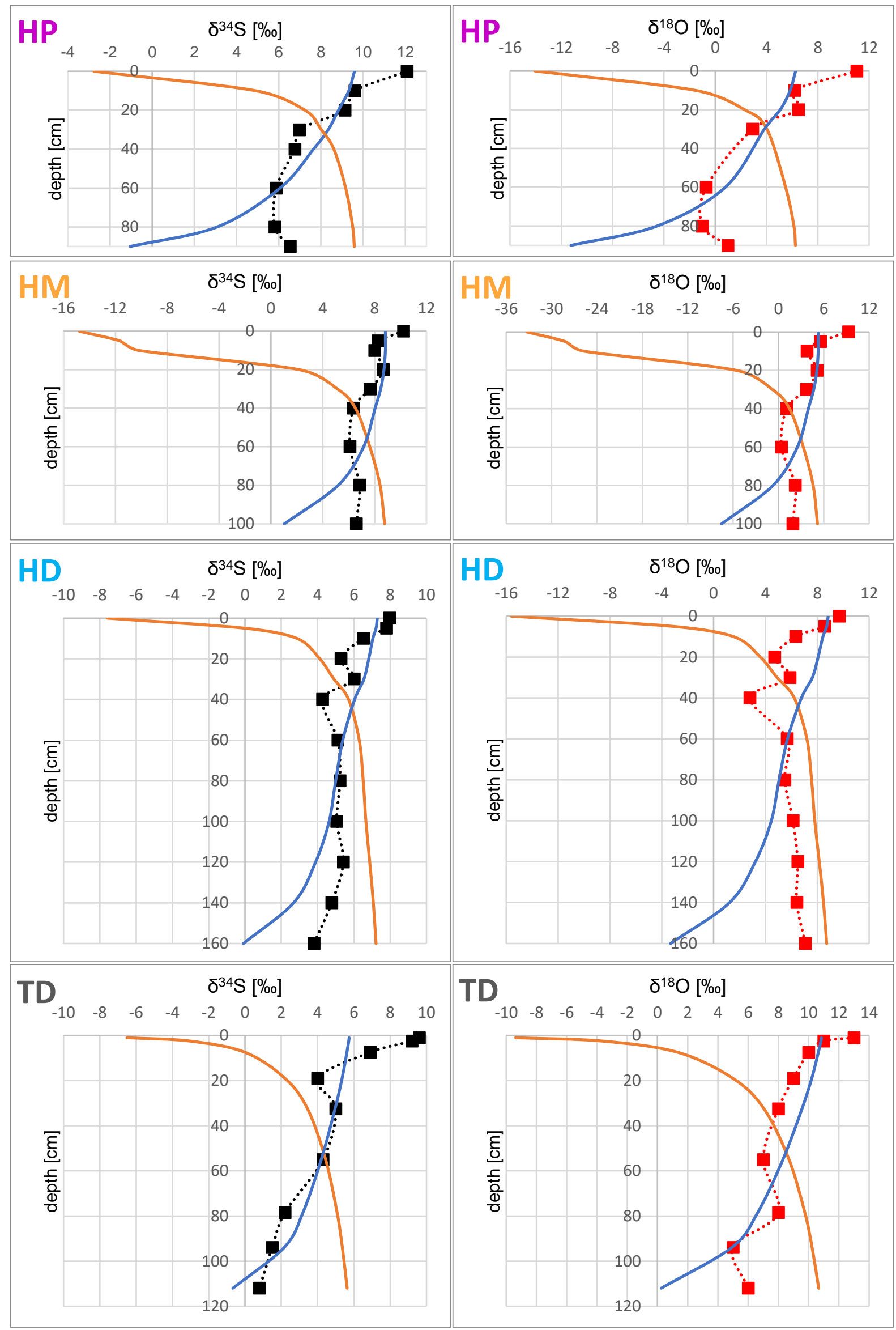

Figure S8 Rayleigh model for $\delta^{34} S$ (black, dotted) and $\delta^{18} \mathrm{O}$ (red, dotted) of each profile. Blue curve results in modeling a downward water flow from top to bottom and the orange curve results in modeling the inverse, upward water flow from bottom to top. 